\title{
Study of Transient Flow and Particle Transport in Continuous Steel Caster Molds: Part I. Fluid Flow
}

\author{
QUAN YUAN, BRIAN G. THOMAS, and S.P. VANKA
}

\begin{abstract}
Unsteady three-dimensional flow in the mold region of the liquid pool during continuous casting of steel slabs has been computed using realistic geometries starting from the submerged inlet nozzle. Three largeeddy simulations (LES) have been validated with measurements and used to compare results between full-pool and symmetric half-pool domains and between a full-scale water model and actual behavior in a thin-slab steel caster. First, time-dependent turbulent flow in the submerged nozzle is computed. The time-dependent velocities exiting the nozzle ports are then used as inlet conditions for the flow in the liquid pool. Complex time-varying flow structures are observed in the simulation results, in spite of the nominally steady casting conditions. Flow in the mold region is seen to switch between a "doubleroll" recirculation zone and a complex flow pattern with multiple vortices. The computed time-averaged flow pattern agrees well with measurements obtained by hot-wire anemometry and dye injection in fullscale water models. Full-pool simulations show asymmetries between the left and right sides of the flow, especially in the lower recirculation zone. These asymmetries, caused by interactions between two halves of the liquid pool, are not present in the half-pool simulation. This work also quantifies differences between flow in the water model and the corresponding steel caster. The top-surface liquid profile and fluctuations are predicted in both systems and agree favorably with measurements. The flow field in the water model is predicted to differ from that in the steel caster in having higher upward velocities in the lower-mold region and a more uniform top-surface liquid profile. A spectral analysis of the computed velocities shows characteristics similar to previous measurements. The flow results presented here are later used (in Part II of this article) to investigate the transport of inclusion particles.
\end{abstract}

\section{INTRODUCTION}

TURBULENT flow during the continuous casting of steel is important, because it influences critical phenomena that affect steel quality. These include inclusion/bubble transport and entrapment, ${ }^{[1,2,3]}$ the transport and dissipation of superheat, ${ }^{[4]}$ the shape and fluctuations of the top-surface level,,$[5,6]$ and the entrainment of mold flux from velocity variations across the top surface. The continuous casting process is schematically shown in Figure 1, during which the molten steel flows into the liquid pool from the tundish through the submerged entry nozzle (SEN). The flow rate is controlled using either a stopper rod (shown in Figure 1) or a slide gate that restricts the opening area. The bifurcated or trifurcated nozzle ports direct molten steel jets into the mold cavity at the desired angle, with various levels of turbulence and swirl. The watercooled mold freezes a thin solid shell, which is continuously withdrawn at the casting speed. The shell contains a large liquid pool in which steel circulates, as shown in Figure 1.

The flow in both the SEN and the liquid pool is highly turbulent, with Reynolds numbers in excess of 10,000. Thus, chaotic turbulent structures exist in the liquid pool even for nominally steady-state casting conditions. This might lead to quality problems. The effect of unsteady flow on quality problems has not been investigated, even though many experimental studies have confirmed that transient flow conditions

QUAN YUAN, Ph.D. Candidate, BRIAN G. THOMAS, W. Grafton and Lillian B. Wilkins Professor, and S.P. VANKA, Professor, are with the Department of Mechanical and Industrial Engineering, University of Illinois at Urbana-Champaign, Urbana, IL 61801. Contact e-mail: bgthomas@ uiuc.edu

Manuscript submitted July 14, 2003. (involving changes in flow patterns) are associated with quality problems. ${ }^{[7]}$ Flow transients influence transport of inclusion particles (e.g., alumina) and bubbles carried by the jets into the liquid pool and might be the cause for intermittent and asymmetrical defects observed in plants. ${ }^{[7]}$ The turbulent jets traverse the liquid pool and impinge on the narrow face to build up an unsteady heat flux, which might cause shellthinning breakouts if the instantaneous flux is too high. ${ }^{[8]}$ The top surface, especially near the meniscus, is responsible for surface quality problems and other defects. A liquid slag layer (Figure 1) covers the molten steel top surface to prevent it from being reoxidized by the air. The liquid flux also creeps into the interfacial gap between the mold and the shell to act as a lubricant to prevent surface defects. Excessive fluctuations of the liquid level at the top surface interrupt the steady supply of the liquid slag into the interfacial gap and cause heat-transfer variations, resulting in longitudinal cracks, ${ }^{[9]}$ transverse depressions, ${ }^{[10]}$ and other defects. ${ }^{[11]}$ The velocity across the top surface also varies with time. Excessive local surface velocity can shear off liquid slag into the liquid pool to form harmful mold-slag inclusions, ${ }^{[12]}$ causing skin delaminations, slivers, and other defects in rolled sheet product. ${ }^{[7]}$ Heat transfer at the top surface is also important. If the surface temperature is too cold and the flow is too slow, the meniscus might solidify to form hooks or deep oscillation marks. Plant observations have found that these defects are intermittent ${ }^{[13]}$ suggesting that they are related to flow transients. The present work aims to generate fundamental insights into the transient flow in the mold region, as an essential step toward minimizing defects in the final steel product.

Many previous studies have used Reynolds-averaged turbulence models (mainly the $k$ - $\varepsilon$ model) to study flow in the liquid pool. ${ }^{[14-22]}$ These models predict time-averaged velocities 
Schematic of continuous casting tundish, SEN, and mold

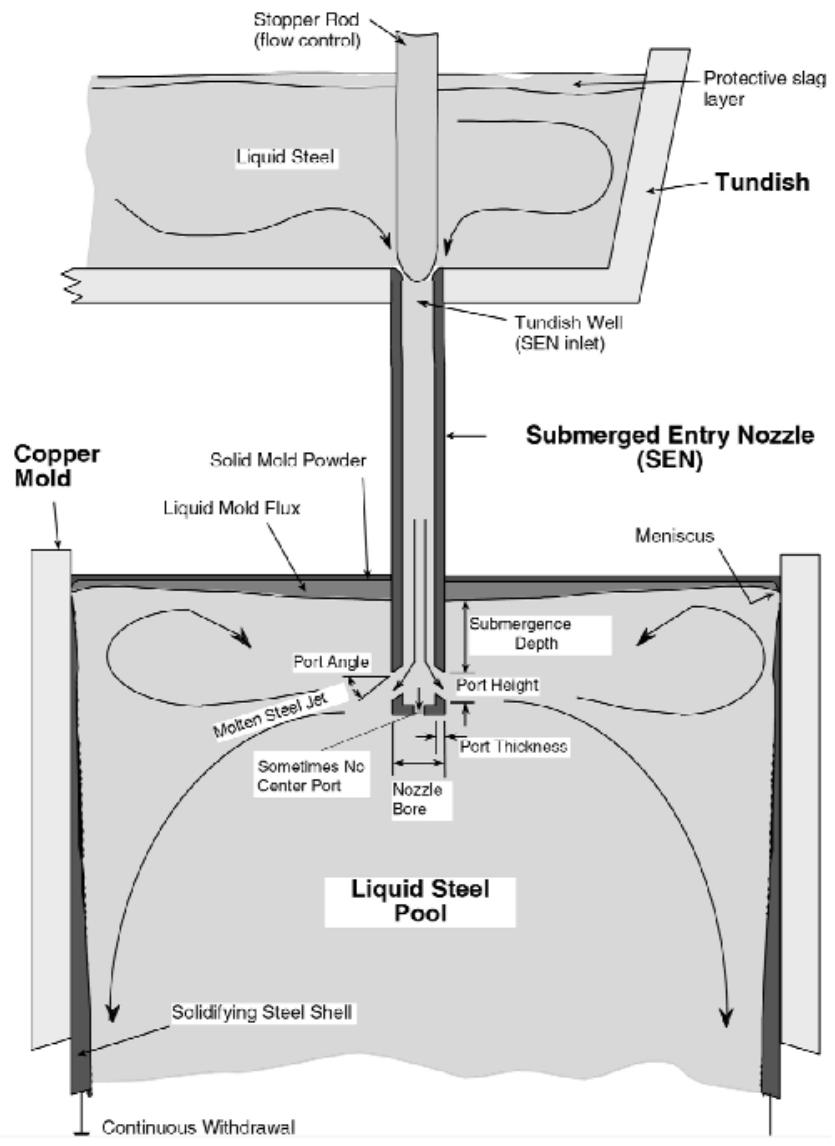

Fig. 1-Schematics of the process of continuous casting of steel.

with reasonable accuracy ${ }^{[21]}$ and at a reasonable computational cost. However, they poorly estimate turbulent dynamics such as quantified by root-mean-square (rms) values. ${ }^{[21]} \mathrm{A}$ transient Reynolds-averaged approach, which is more computationally demanding, was used previously to study transient changes in flow pattern resulting from drastic changes in inlet conditions. ${ }^{[23]}$ However this approach was unable to capture inherent flow transients during steady casting in several test cases. This may be due to the large numerical dissipation associated with these models, or due to the assumption of isotropic turbulence.

The present work employs the large-eddy simulation (LES) approach. This approach was shown in recent studies to accurately predict the dynamics of large-scale turbulence structures during continuous casting of steel. ${ }^{[21,22,24-26]}$ However, LES entails many challenges when applied to this complex flow problem, including the prescription of the transient inlet velocities, resolution of the complex domain geometry, the moving solidification front, and computing long-term transients. Therefore, the application of LES to these aspects of continuous casting requires large amounts of computer memory and central processing unit (CPU) time. As a result, this model may be considered as a way to generate fundamental understanding and benchmarks for simple models rather than as an engineering tool for parametric study.

Due to the high operating temperature, it is difficult and expensive to conduct flow measurements in continuous steel casters in order to validate model predictions. ${ }^{[21]}$ However, because of the nearly equal kinematic viscosities of molten steel and water, water models with transparent plastic walls can be used to study single-phase flow in steel casting processes, ${ }^{[27,28,5,29-32]}$ where Froude similarity is usually employed. Thus, measurements using dye injection, hot-wire anemometry, and particle-image velocimetry (PIV) to quantify the flow velocities in water models are used to validate the predictions of the LES code in this work.

Although very valuable for validation of computational models, the water model differs from the actual steel caster in several aspects important to the flow field. First, its sidewalls, which represent the moving solidifying shell front, are nonporous and stationary. Further, the water model has a flat bottom with outlet ports instead of the long tapering molten-steel pool. These two major differences give rise to different flow phenomena, as this work will show.

Three simulations are presented in this article to understand the differences between full-pool and symmetric halfpool domains and between a full-scale water model and real steel-caster behavior. The first simulation (case 1) is on a full-scale water model corresponding to a standard slab caster. A symmetry condition was imposed at the center plane between narrow faces, so only half of the physical liquid pool (Figure 2(a)) is simulated (Figure 2(b)). The next two cases simulate the full pool of a thin-slab caster water model (case 2-W) and its corresponding steel caster (case $2-S$ ). Detailed information on the computational model and the three simulations are given in the next section. This is followed by results from the three simulations. Comparisons with measurements are made where available, including velocities along the jet and across the top surface, the profile of the top-surface liquid level, and a spectral analysis. The turbulent flow structures in the pool are presented, along with the transient flow asymmetries. The flow field is quantified with the time-averaged and root-mean-square velocities along the jets, across the top surface, and in the lower recirculation zone. This article also quantifies the differences between the velocity field in the water model and the corresponding steel caster, including the top-surface liquid profile.

\section{MODEL DESCRIPTION}

The unsteady three-dimensional Navier-Stokes equations governing the flow field are given by

$$
\begin{gathered}
\frac{\partial v_{i}}{\partial x_{i}}=0 \\
\frac{D v_{i}}{D t}=-\frac{1}{\rho} \frac{\partial p}{\partial x_{i}}+\frac{\partial}{\partial x_{j}} v_{\text {eff }}\left(\frac{\partial v_{i}}{\partial x_{j}}+\frac{\partial v_{j}}{\partial x_{i}}\right)
\end{gathered}
$$

where

$$
\begin{gathered}
v_{\text {eff }}=v_{0}+v_{t} \\
v_{t}=0.01(\Delta x \Delta y \Delta z)^{2 / 3} \sqrt{\frac{\partial v_{i}}{\partial x_{j}} \frac{\partial v_{i}}{\partial x_{j}}+\frac{\partial v_{i}}{\partial x_{j}} \frac{\partial v_{j}}{\partial x_{i}}}
\end{gathered}
$$

In the context of an LES, these velocities represent the largescale eddies, with the influence of small-scale eddies being represented by subgrid-scale (SGS) models. In the previous equations, $v_{i}$ is the three-dimensional time-dependent velocity vector representing the motion of large eddies, and $\Delta x, \Delta y$, 


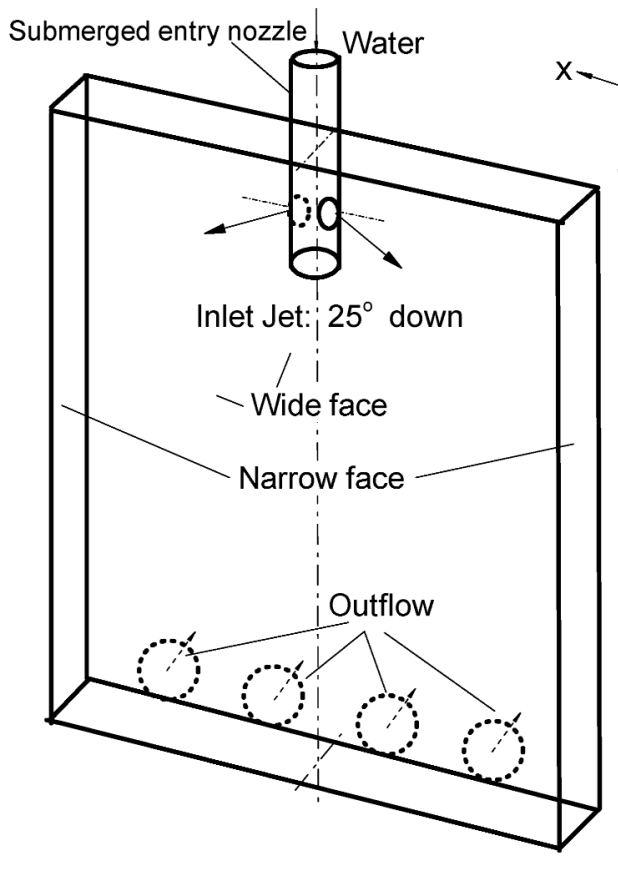

(a)

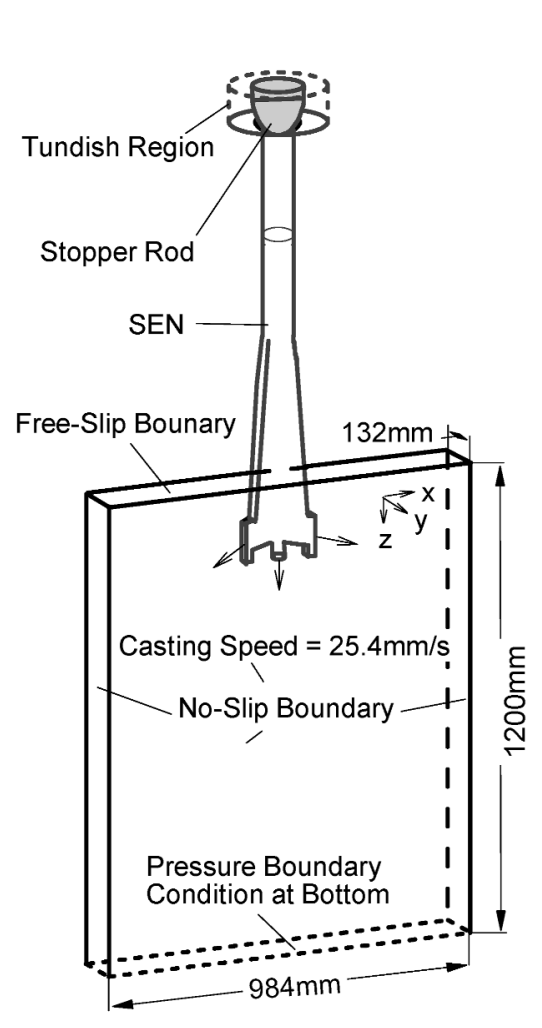

(c)

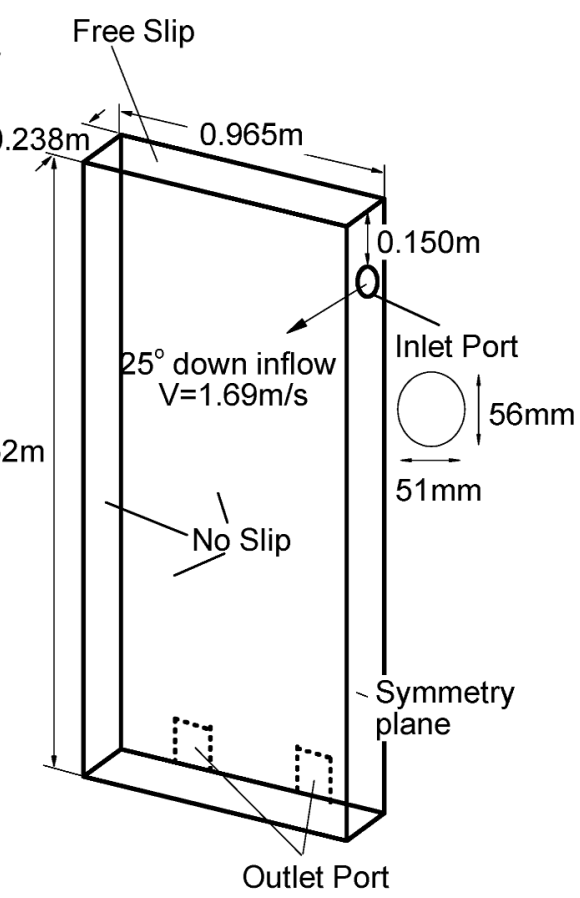

(b)

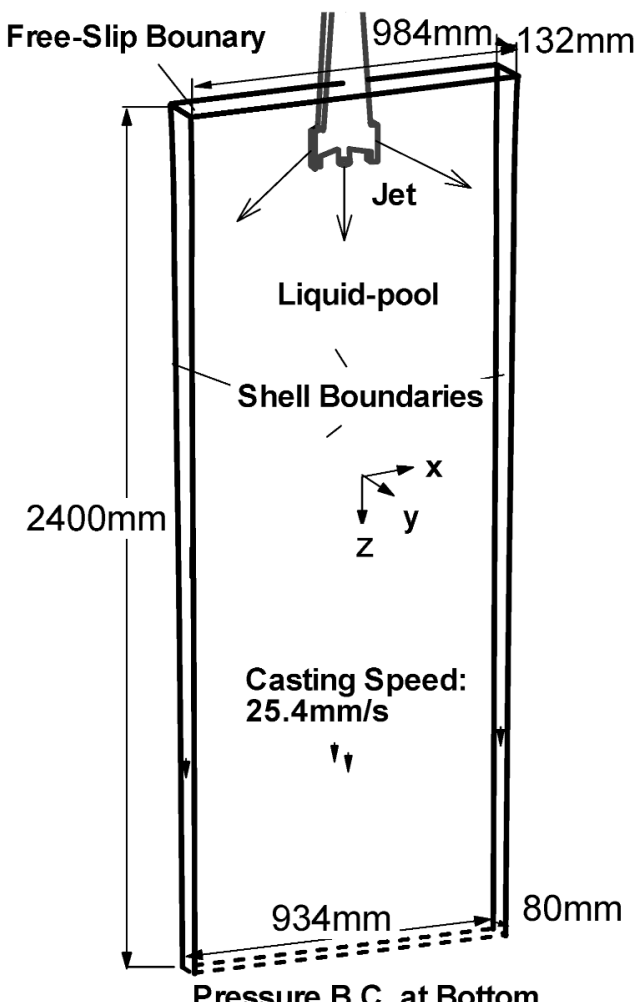

Pressure B.C. at Bottom

(d)

Fig. 2-Schematics of (a) the physical water model of case 1 and $(b)$ its computational domain and the thin slab caster $(c)$ case 2-W and $(d)$ case 2-S.

and $\Delta z$ are the size of each cell in the Cartesian computational grid. The eddy viscosity $\left(v_{t}\right)$ can be computed using SGS models to represent the dissipative effect of the unresolved small eddies. It vanishes if the grid resolution is capable of resolving the smallest eddies (Kolmogorov scale). Equation [4] describes the evolution of the traditional
Smagorinsky SGS model, ${ }^{[33]}$ which was used in the first computation as a preliminary exercise. In the other two computations, the eddy viscosity was set to zero. These no-SGS model simulations could be interpreted as coarse-grid direct numerical simulations, as the effect of the SGS model was considered to be small, as discussed elsewhere. ${ }^{[34]}$ 


\section{A. Boundary Conditions}

\section{Inlet}

The liquid pool is fed by a bifurcated (case 1) or trifurcated (case 2) nozzle, which has an important influence on the flow pattern. ${ }^{[21]}$ Thus, nozzle simulations were first conducted to acquire accurate inlet conditions. Unsteady flow velocities leaving the nozzle ports were collected every 0.001 seconds. The time-dependent velocities were stored and then recycled periodically as the inlet conditions for the liquid-pool simulations. More details of the inlet-nozzle simulations are given later.

\section{Outlet}

One of the important differences between water models and steel casters is that water models have outlet ports on their plastic bottom or side walls, while in steel casters, the liquid pool gradually tapers to a solid end. In this work, the computational domain of the water model (case 1) is the same as the physical model. However, the domain extent of the thin-slab caster (case 2) is limited by computational resources. For computational efficiency, simulations of case 2 only compute flow in the mold liquid pool from the top surface to a depth of $1.2 \mathrm{~m}$ (water model) or $2.4 \mathrm{~m}$ (steel caster) below the top surface. This creates an artificial outlet plane where flow leaves the computational domain. In current simulations, a constant-pressure boundary condition, with zero gradient of other variables, was used at this plane, where the flow becomes nearly uniform.

\section{Top-surface and symmetry-center plane}

The symmetry plane condition was only imposed in the halfpool simulation (case 1). A free-slip condition was imposed along both the top surface and the center plane. Specifically, along these two boundaries, the normal velocity was constrained to zero, and the normal gradients of pressure and the other two velocity components were set to zero. The predictions and measurements of this work (presented in section III-H) suggest that the top surface is relatively quiescent, so no model of free-surface deformation is necessary to accurately model the flow. The effect of the symmetry plane condition is investigated by comparing full-pool and half-pool simulations.

\section{Narrow-face and wide-face walls}

Water models and steel casters are very different at the narrow- and wide-face walls. Water models have stationary straight plastic side walls representing the solidification front. Thus, all three velocity components were set to zero at the wall boundary. However, flow in the steel caster was mod- eled up to, but not including, the front of the downwardmoving mushy zone, ${ }^{[20]}$ where solidification occurs to take away mass from the molten steel pool. This required tapering the domain walls to include only the liquid pool. To further account for the solidification and downward motion, a velocity boundary condition given by Eq. [5] was used:

$v_{x}=V_{n} \cos \theta-V_{t} \sin \theta=\left(\frac{\rho_{s}}{\rho_{l}}-1\right) \sin \theta \cos \theta V_{\text {casting }}$ [5a]
$v_{z}=V_{n} \sin \theta+V_{t} \cos \theta=\left(\frac{\rho_{s}}{\rho_{l}} \sin ^{2} \theta+\cos ^{2} \theta\right) V_{\text {casting }}[5 \mathrm{~b}]$

Derivation of Eq. [5] can be found in the Appendix. In both systems, no wall functions were used to represent near-wall turbulence, because of a relatively fine mesh near the wall.

\section{B. Solution Procedure}

The time-dependent three-dimensional Navier-Stokes equations are discretized using the Harlow-Welch fractionalstep procedure. ${ }^{[35]}$ Second-order central differencing is used for the convection terms, and the Crank-Nicolson scheme ${ }^{[36]}$ is used for the diffusion terms. The Adams-Bashforth scheme $^{[37]}$ is used to discretize in time with second-order accuracy. The pressure Poisson equation is solved using either a fast-Fourier-transform (FFT) solver ${ }^{[38]}$ in case 1 with a structured grid or an algebraic multigrid (AMG) solver ${ }^{[39]}$ in case 2 with unstructured Cartesian grids.

\section{Computational Details}

The three computational domains are presented in Figure 2. The geometry, casting conditions, material properties, and computational parameters are given in Table I. For computational efficiency, the domain was divided into the nozzle and liquid-pool regions. Flow in each region was computed separately. Nozzle simulations were first performed, from which transient velocities exiting the nozzle ports were collected and used as conditions at the pool inlet.

\section{Case 1}

Figure 2(a) shows the physical water model of a standard slab caster (case 1). Water enters the liquid pool from the bifurcated nozzle ports at a downward angle of approximately $25 \mathrm{deg}$. Water exits the model from four outlet pipes near the bottom of the wide face, as shown in Figure 2(a). Detailed geometry and operation conditions are published elsewhere. ${ }^{[1,28]}$

Table I. Properties and Conditions of the Simulations

\begin{tabular}{|c|c|c|c|}
\hline Parameter/Property & Case 1 & Case 2-W & Case 2-S \\
\hline Mold width (mm) & 1830 & 984 & 984 \\
\hline Mold thickness (mm) & 238 & 132 & 132 \\
\hline Water model length (mm) & 2152 & 2600 & - \\
\hline Mold length (mm) & - & - & 1200 \\
\hline Domain width (mm) & 238 & 984 & 984 (top) 934.04 (domain bottom) \\
\hline Domain thickness (mm) & 238 & 132 & 132 (top) 79.48 (domain bottom) \\
\hline Domain length $(\mathrm{mm})$ & 2152 & 1200 & 2400 \\
\hline Nozzle port height $\times$ thickness $(\mathrm{mm} \times \mathrm{mm})$ & $51 \times 56$ (Fig. 2) & $75 \times 32$ (inner bore) & $75 \times 32$ (inner bore) \\
\hline Bottom nozzle port diameter $(\mathrm{mm})$ & - & 32 & 32 \\
\hline SEN submergence depth $(\mathrm{mm})$ & 150 & 127 & 127 \\
\hline Casting speed $(\mathrm{mm} / \mathrm{s})$ & 15.2 & 25.4 & 25.4 \\
\hline Fluid kinematic viscosity $\left(\mathrm{m}^{2} / \mathrm{s}\right)$ & $1.0 \times 10^{-6}$ & $1.0 \times 10^{-6}$ & $7.98 \times 10^{-7}$ \\
\hline
\end{tabular}


This half-pool simulation adopted velocity profiles from a prior turbulent-pipe flow simulation as the inlet velocities from the small, elliptical nozzle ports. The pipe was $38 \mathrm{pct}$ open at its entry, where a constant velocity was imposed. Transient velocities were collected 7.5 pipe diameters away from the pipe entry for 1.6 seconds and then rotated $25 \mathrm{deg}$ downward to feed the pool simulation.

Figure 2(b) shows the half-pool computational domain with a symmetry condition at the pool center. The nozzle port was modeled as an opening on the symmetry plane. The outlet ports, which are far from our flow region of interest, were approximated as square openings with the same area as the physical ports. This computational domain was discretized with a structured Cartesian grid consisting of 1.6 million cells. The time step of the simulation was 0.0008 seconds.

\section{Case 2}

Domains of a thin-slab steel caster (case 2-S) and its water model (case 2-W) are presented in Figures 2(d) and (c), respectively. Both systems used the same 1.1-m-long inlet nozzle, starting from the tundish bottom and fed through the annulus formed by a 64.4 pct open stopper rod, down a 70 -mm-diameter round-bore upper nozzle that tapered into a thin trifurcated outlet region. A prior nozzle simulation with realistic geometry was performed with a 0.6-million-cell mesh using an unstructured Cartesian cell code. Time-dependent velocities leaving the trifurcated nozzle ports were stored every 0.025 seconds for 9.45 seconds (10-day computation on a Pentium IV 1.7 $\mathrm{GHz} \mathrm{CPU}$ ) to be used as inflow to the liquid pool.

Figure 2(d) shows that the domain of the steel caster has a curved side boundary, which represents the solidifying front at the liquidus temperature. The boundary shape was obtained from the prediction of an in-house code, CON1D,${ }^{[40,41]}$ which is shown to agree with measurements (Figure 3) on a breakout shell. ${ }^{[42]}$ It should be noted that the symmetry-plane assumption was not needed in the two full-pool simulations. There is no argon gas in any of the simulations in order to match the real caster, where calcium treatment was used to avoid nozzle clogging.

Unstructured Cartesian grids consisting of 0.7 and 1.3 million cells were employed for the water-model and the steel caster simulations, respectively. The latter grid features cells centered $0.25 \mathrm{~mm}$ from the wall in the upper mold, including the impingement region. This half-cell size gradually increases

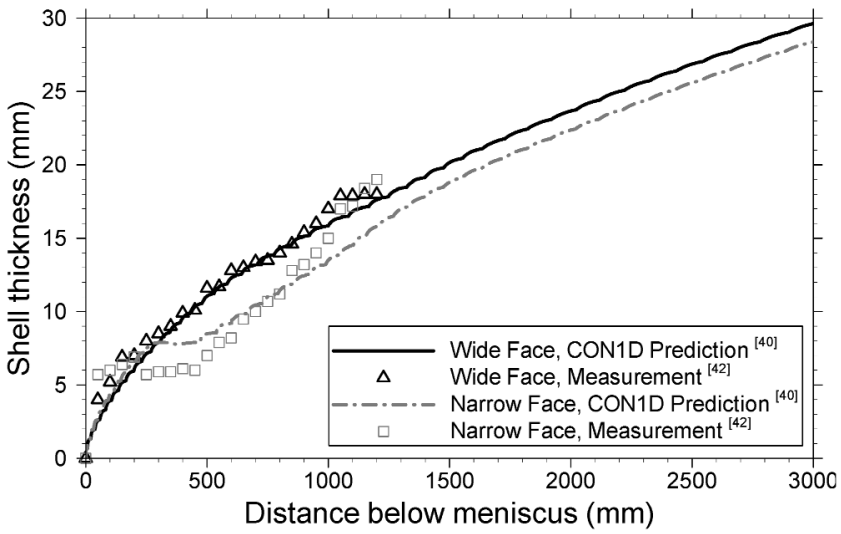

Fig. 3-Predicted steel shell thickness of case 2-S using CON1D, ${ }^{[40,41]}$ compared with measurements. ${ }^{[42]}$ to a maximum of $7.1 \mathrm{~mm}$ in the lower-gradient interior of the domain. The time step of 0.001 seconds was used in both simulations. The simulation took 29.5 CPU seconds per time step on a Pentium IV $1.7 \mathrm{GHz}$ CPU for the 1.3-million-cell grid, or 24 days for 70,000 time steps (70 seconds of real time) with the AMG solver. Compared to the AMG, the FFT solver is about 4 times faster and takes about one-quarter of the memory. However, it is not suitable for the complex geometries that are necessary to represent the actual caster.

\section{RESULTS}

\section{A. The Standard Slab-Caster Water Model (Case 1)}

Case 1 is a half-pool simulation to model a typical slab caster with bifurcated nozzles. Its transient inflow velocities, obtained from the prior pipe simulation, are averaged temporally and shown in Figure 4(a). Higher velocities are revealed

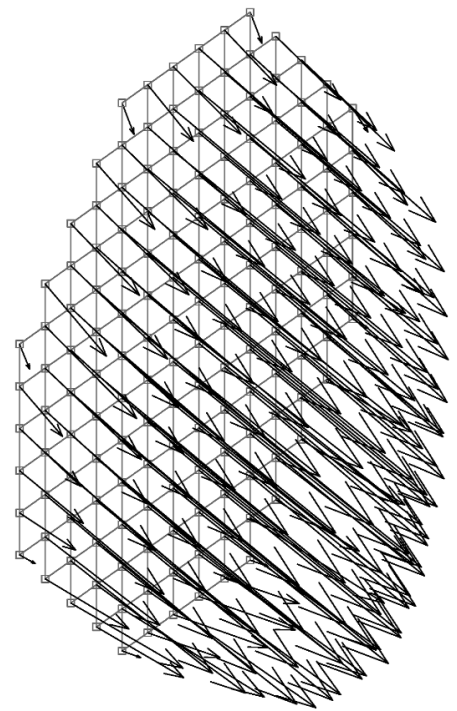

(a)

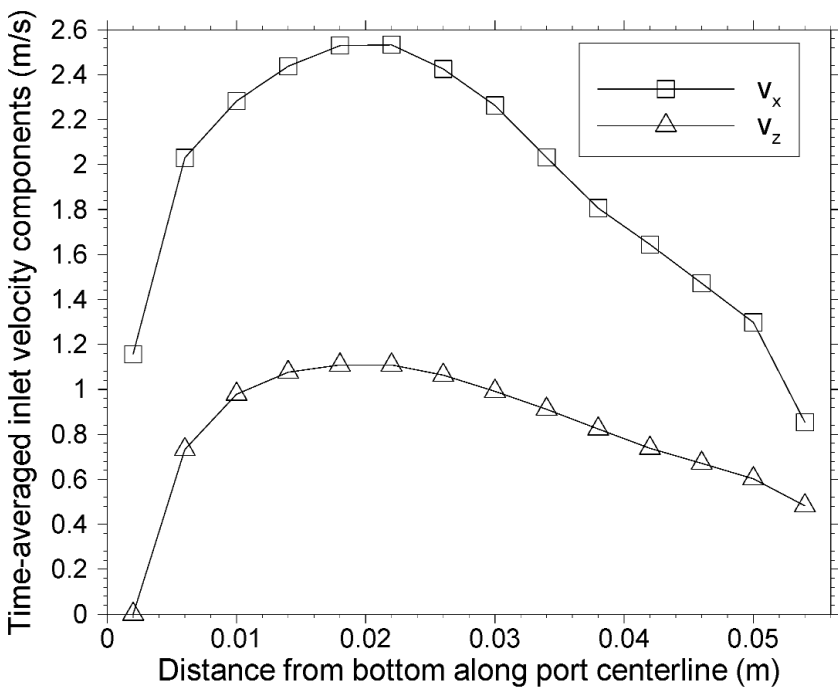

(b)

Fig. 4-Inlet velocities of the standard slab caster water model: (a) timeaveraged velocity vectors at the inlet port and $(b)$ transverse $(x)$ and downward $(z)$ velocity components along nozzle port centerline. 
in the lower portion. This is consistent with previous measurements and predictions on similar nozzles. ${ }^{[43,44]}$ The outward and downward velocity components along the port centerline are depicted in Figure 4(b), with maximum values at approximately one-third of the distance from the port bottom.

A typical instantaneous velocity field in the liquid pool is shown in Figure 5. Water emerges from the inlet port as a jet, diffuses as it traverses across the liquid pool, impinges on the narrow face, and splits into two recirculation zones consisting of complex structures. The predicted flow pattern matches experimental observations. ${ }^{[1,28]} \mathrm{A}$ closer view of the turbulent structures in the upper roll is presented in Figures 6(a) and (b) for two time instants. The figures show that the upper roll consists of a relatively simple vortex at the first instant, which evolves to a pattern involving more complex multiple vortices at the second instant. The upper roll alternates irregularly between the two extremes in the simulation. It is also found that only close to the top surface is the velocity direction consistently horizontal. This is important in understanding the accuracy of the indirect measurement of the flow velocity in

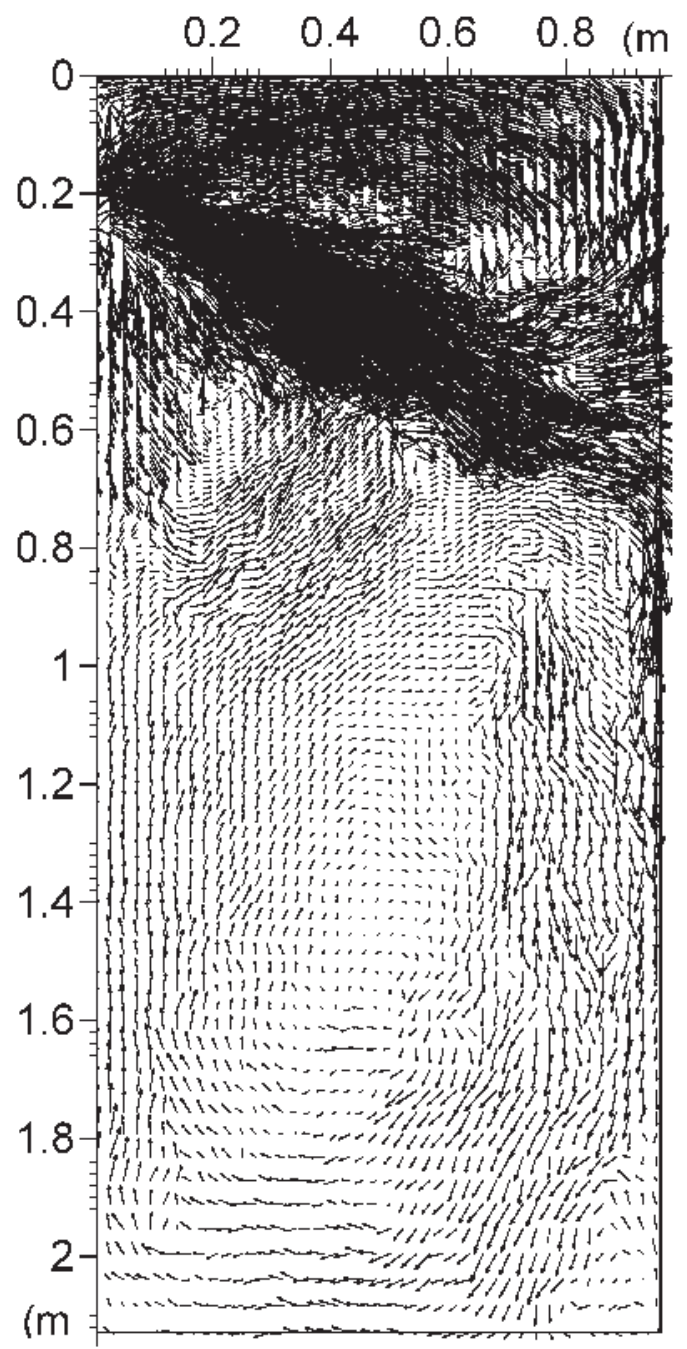

$$
\text { (Scalc: } \rightarrow 0.25 \mathrm{~m} / \mathrm{s} \text { ) }
$$

Fig. 5-Typical instantaneous velocity vector plot at the center plane between wide faces (case 1), obtained from simulation. steel casters using electromagnetic sensors, ${ }^{[24]}$ which requires a consistent flow direction passing the sensors.

Figure 7 compares the results of the simulation with measurements. The time-averaged speed $\left(\left(v_{x}^{2}+v_{y}{ }^{2}\right)^{1 / 2}\right)$ of the fluid was measured using hot-wire anemometers in a previous work. ${ }^{[28]}$ The measurement was made along four vertical lines in the center plane at specified distances from the SEN. The computation agrees reasonably well with the measurements. The biggest discrepancy occurs along the line $460 \mathrm{~mm}$ from the SEN, where the predicted maximum-speed location is approximately $100 \mathrm{~mm}$ deeper than the measurement in set 1 . This might be due to uncertainties in the measurements. It should be noted that significant differences exist between the measured time averages taken at different times, likely due to insufficient time for calculating statistics. More validations of our simulations were made on a 0.4 -scale water model and are published elsewhere. ${ }^{[21,24]}$ They show good agreement between prediction and PIV measurements.

\section{B. The Trifurcated Inlet Nozzle of Thin-Slab Caster (Case 2)}

A realistic nozzle simulation was conducted to generate accurate unsteady inlet velocities for the computations in the

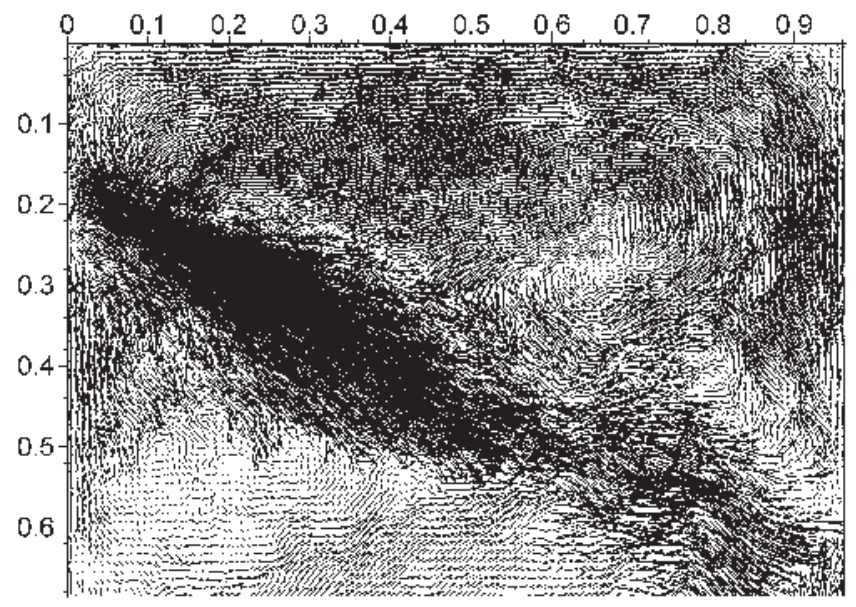

(Scale : $\cdot 0.25 \mathrm{~m} / \mathrm{s}$ )

(a)

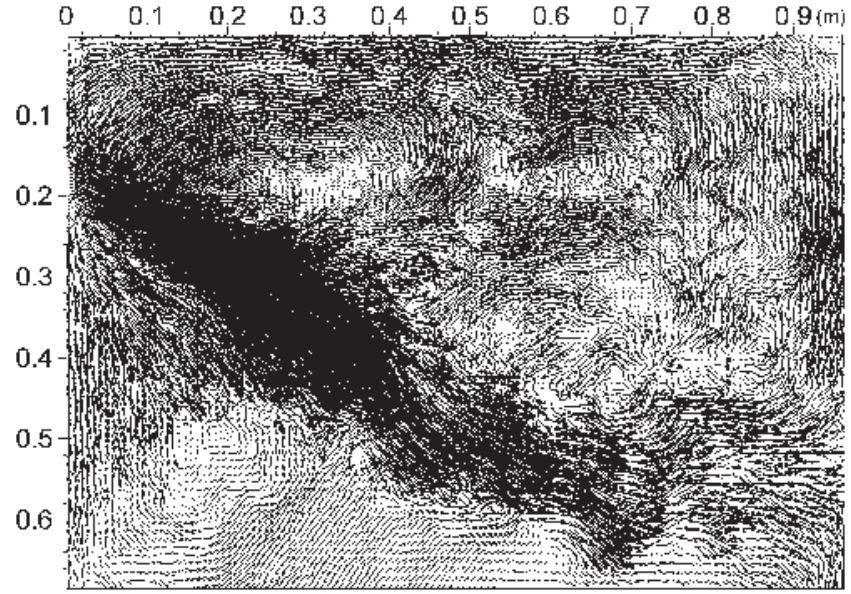

(b)

Fig. 6-Predicted chaotic flow patterns in the upper recirculation zone (case 1): (a) simple vortices and (b) complex multiple vortices. 


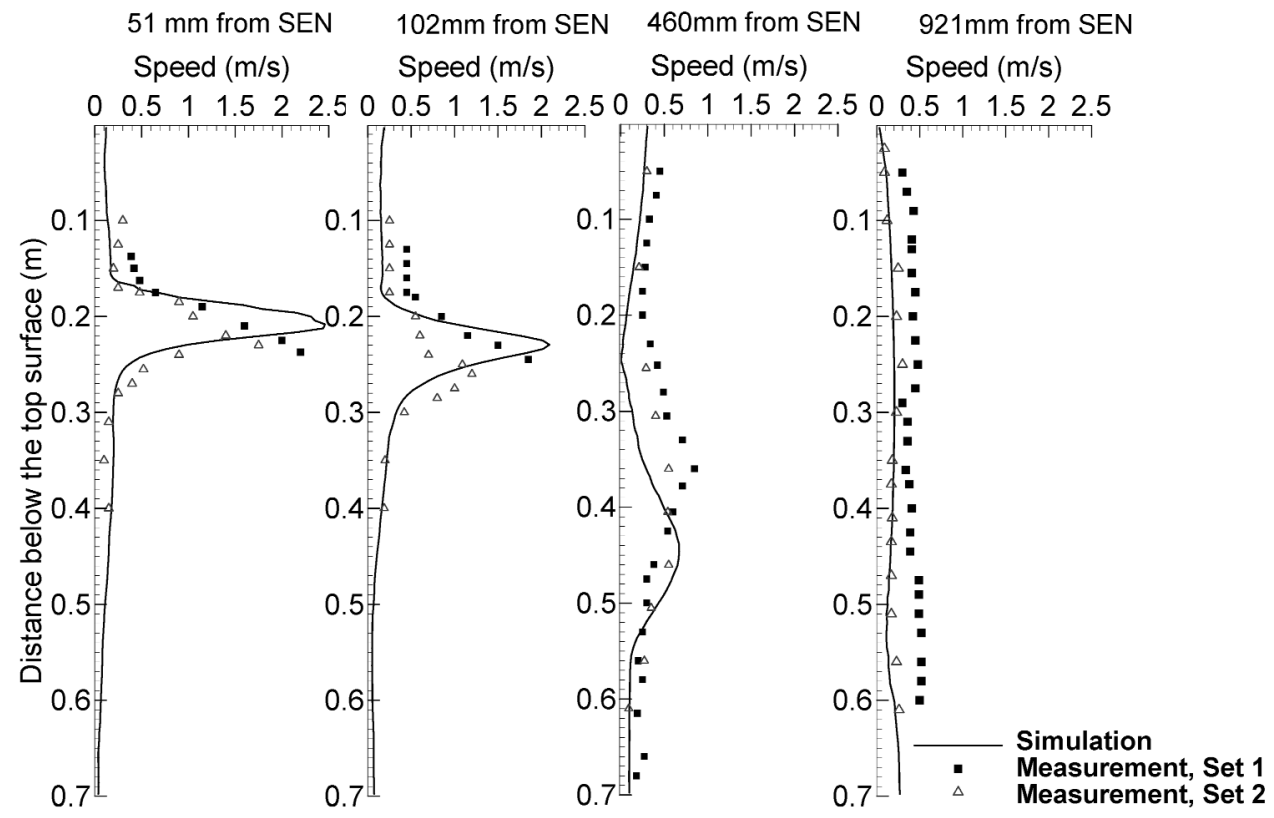

Fig. 7-Comparison of the prediction and measurement of the time-averaged speed $\left(v_{x}^{2}+v_{z}^{2}\right)^{1 / 2}$ along four vertical lines at different distances from SEN (case 1).

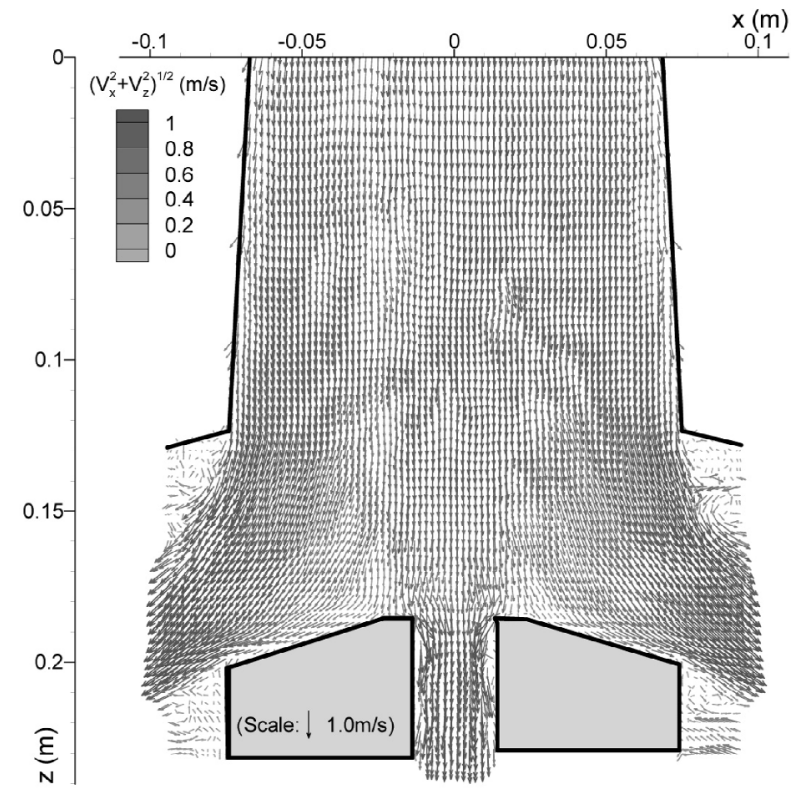

(a)

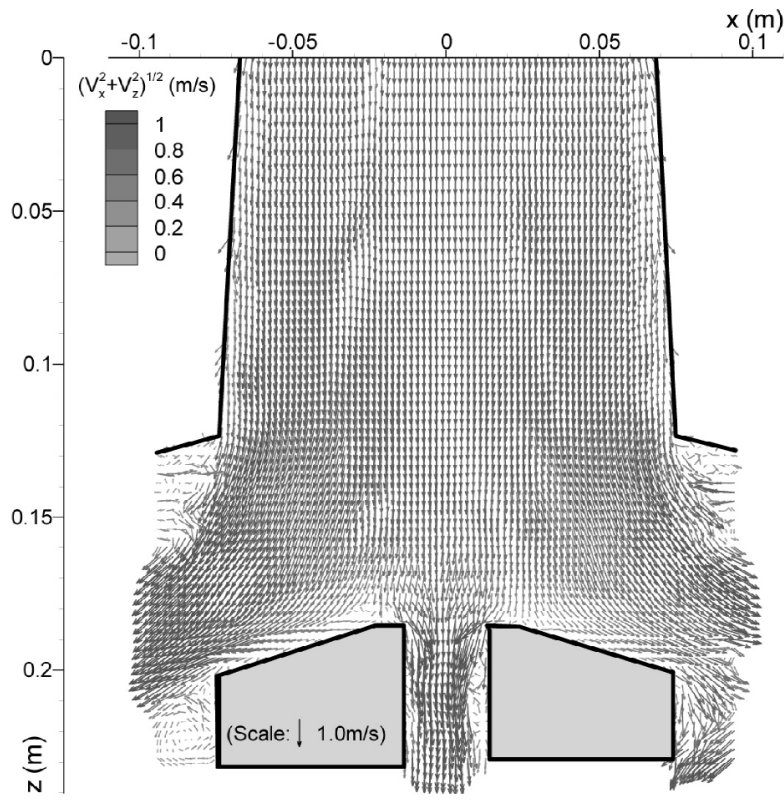

(b)

Fig. 8-Typical instantaneous velocity fields near nozzle ports at the center plane between wide faces, obtained from a large eddy simulation of the nozzle (cases $2-\mathrm{W}$ and $2-\mathrm{S}$ ).

thin-slab caster. The computed results are presented in Figures 8 through 11. Two typical transient flow patterns are plotted in Figure 8, showing flow exiting the nozzle ports at different instants. Supplementary to the vector length, the darkness of the arrow also represents the velocity magnitude. In Figure 8(a), a symmetrical flow pattern is observed between the side ports, while it is apparently asymmetrical in Figure 8(b). The downward angle of the two side jets varies in time from $\sim 30$ to $45 \mathrm{deg}$. The two side jets switch between the two extremes. The jet angle is important, because it greatly affects the transport of harmful inclusions carried by the jet entering the liquid pool. Jets at a deeper angle tend to transport more inclusions into the lower roll, encouraging the formation of internal defects such as slivers and blisters (discussed in more detail in Part II of this article). The jet angle is also important, as it influences the velocity and the profile of the topsurface liquid level. Jets at smaller downward angles are likely to increase the velocity and the liquid-level fluctuations along the top surface, by carrying more fluid and momentum into the upper roll. This can cause quality problems as discussed in the previous sections. Accurate prediction of this angle is essential for optimizing the nozzle design. The center-jet 


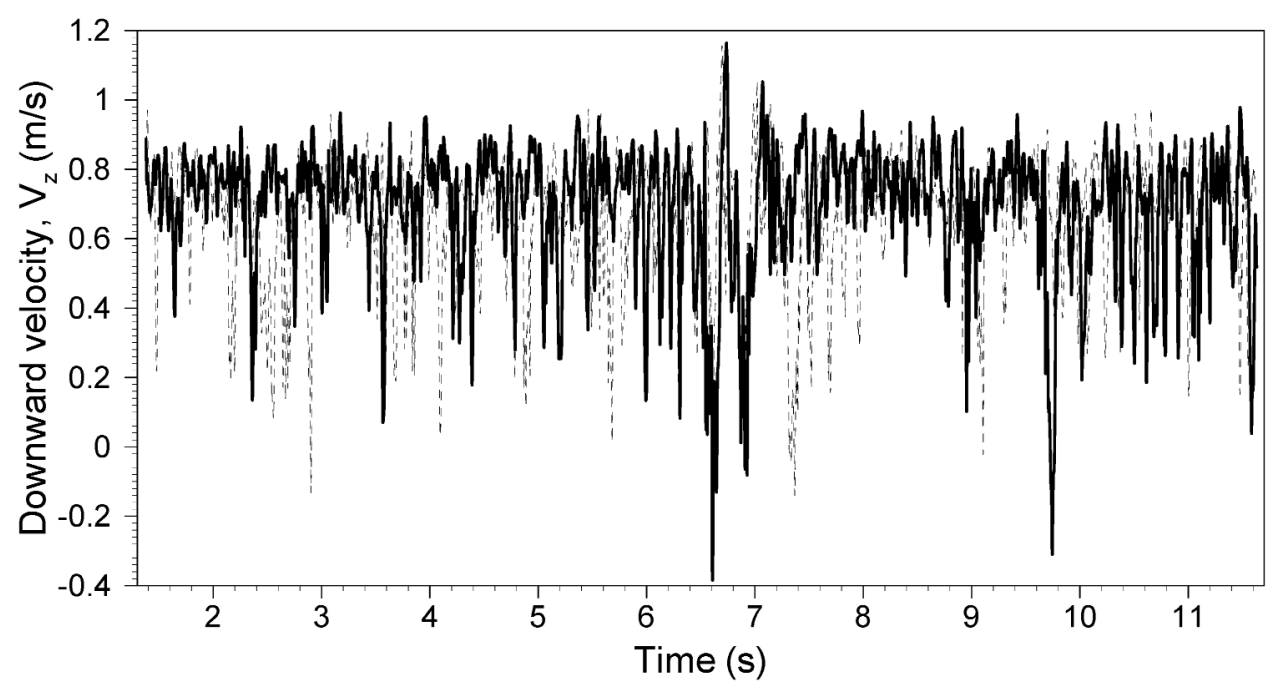

Fig. 9-Time variation of downward velocity $\left(v_{z}\right)$ at two symmetrical points on the side nozzle ports.

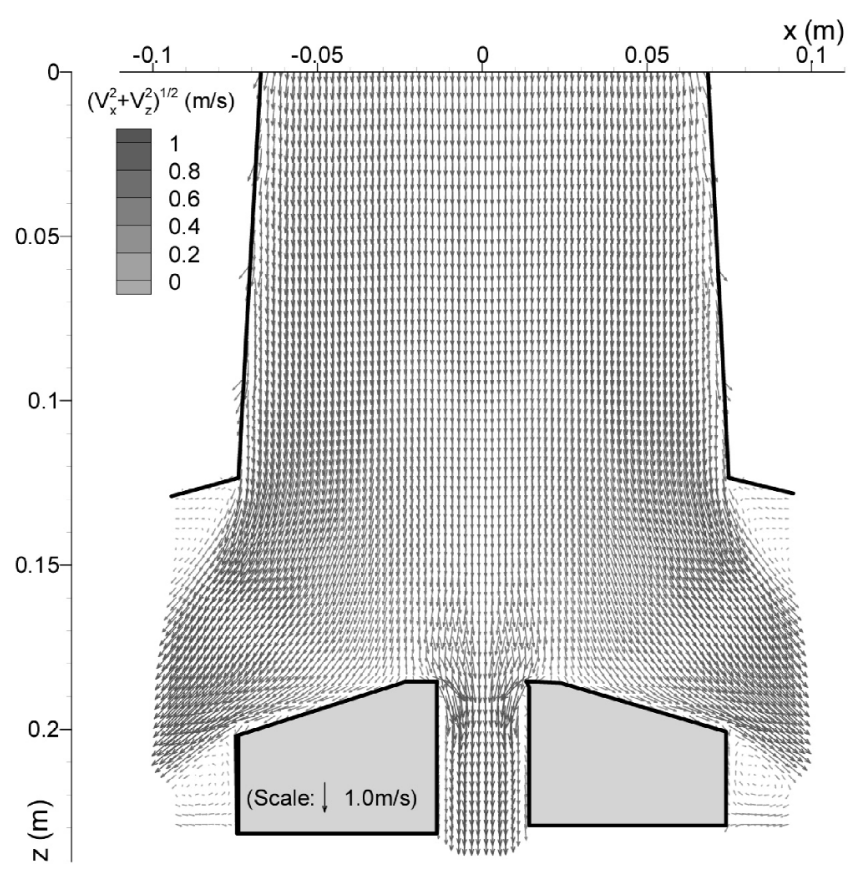

Fig. 10-Time-averaged velocity fields near nozzle ports at the center plane between narrow faces, obtained from the simulation (cases 2-W and 2-S).

velocity is seen to fluctuate considerably, but the flow pattern in the mold stays nearly the same.

Figure 9 shows the fluctuation of the downward-velocity component $\left(v_{z}\right)$ sampled at two points, which are symmetrically located on the side-port outlet plane with a distance $40 \mathrm{~mm}$ below the upper edge. Both signals show a mean value of $\sim 0.6 \mathrm{~m} / \mathrm{s}$, but with significant fluctuations. The highest frequency of the signals is around $10 \mathrm{~Hz}$. The velocity component is mostly positive, indicating that the flow is mostly downward with occasional upward excursions. Shortterm velocity differences are observed between the two sides. However, averaging over a short time is seen to result in approximately the same flow field (Figures 10 and 11).

The computed transient velocity fields in the nozzle were averaged over 9.45 seconds (37,800 time instants) and are

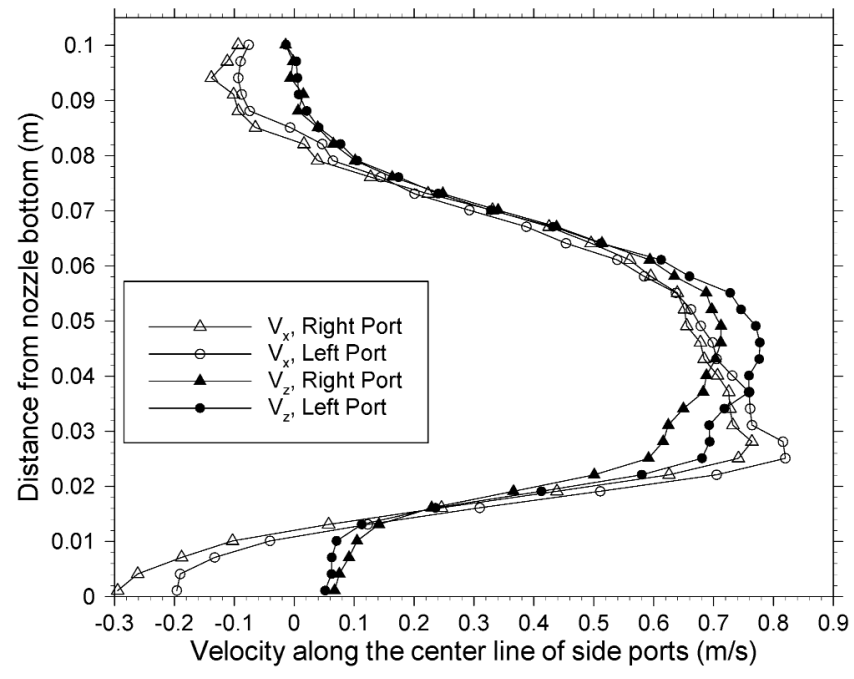

Fig. 11-Time-averaged velocities along the nozzle port centerline on both sides.

plotted in Figure 10. The velocities of the side jets are quantitatively shown in Figure 11 along the nozzle-port center line. The mean of the side jets is very symmetrical even for a short time (9.45 seconds) of average. Most of the fluid exist the ports from the port center region ( 20 to $80 \mathrm{~mm}$ below the upper edge), with some small backflow near the upper and lower edges, where the fluid re-enters the nozzle.

\section{The Thin-Slab Water Model (Case 2-W)}

The transient velocities obtained from the trifurcated-nozzle simulation were then used as inflow into the thin-slab watermodel computation. Before showing the computational results, Figure 12 first presents snapshots of the dye-injection experiment on the water model at four instants, showing the evolution of the transient flow in the liquid pool. Figure 12(a) is at $0.5 \mathrm{sec}-$ onds after the dye exits the nozzle ports, showing instantaneous jet angles of $\sim 42 \mathrm{deg}$ (left-hand side) and $\sim 35 \mathrm{deg}$ (right-hand side). The dye flows with the jet and impinges the narrow face 0.7 seconds later, as shown in Figure 12(b). It then splits 

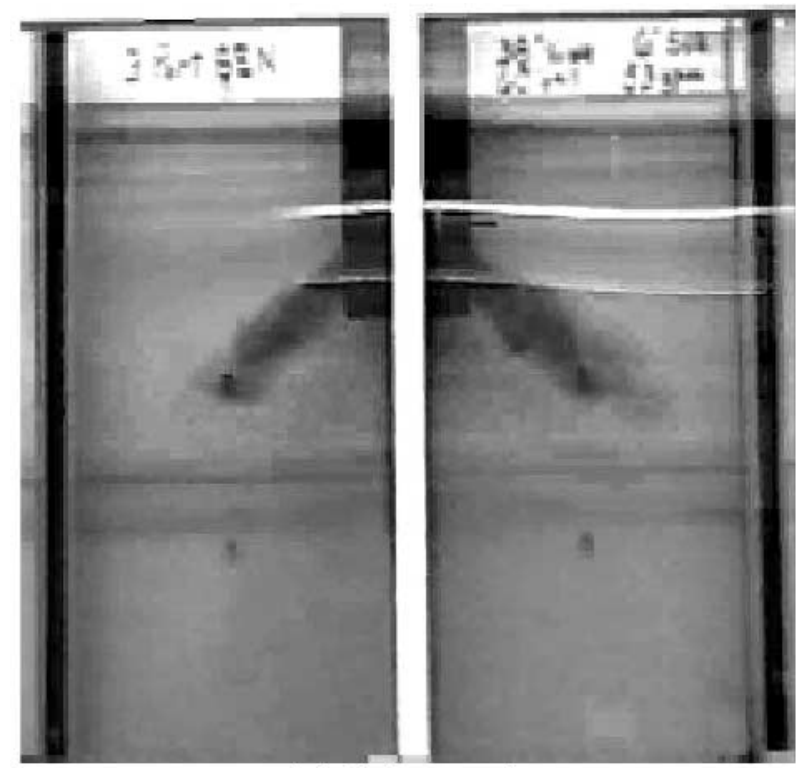

(a) 0.5 seconds
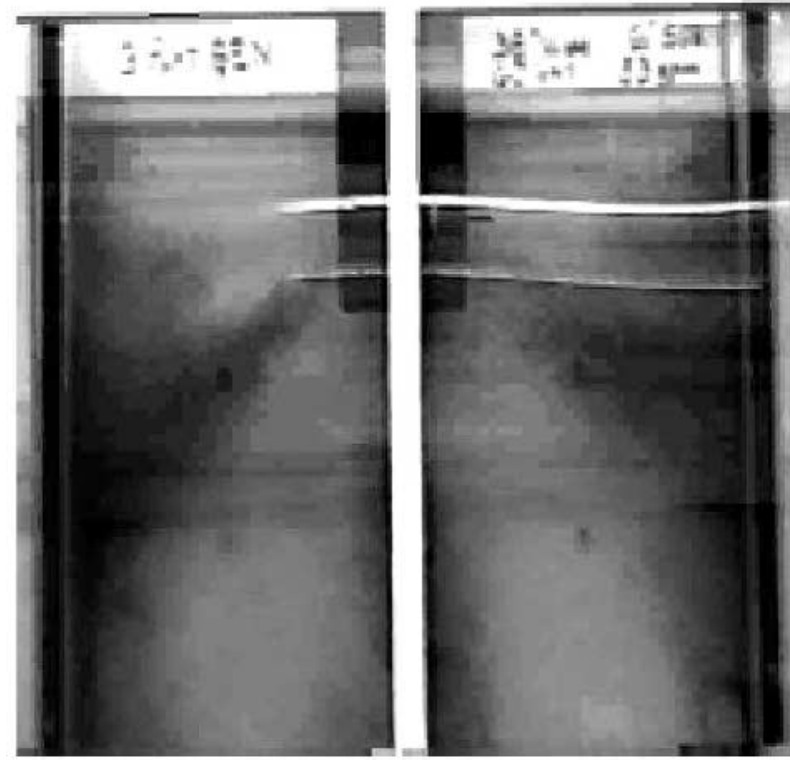

(c) 2.8 seconds
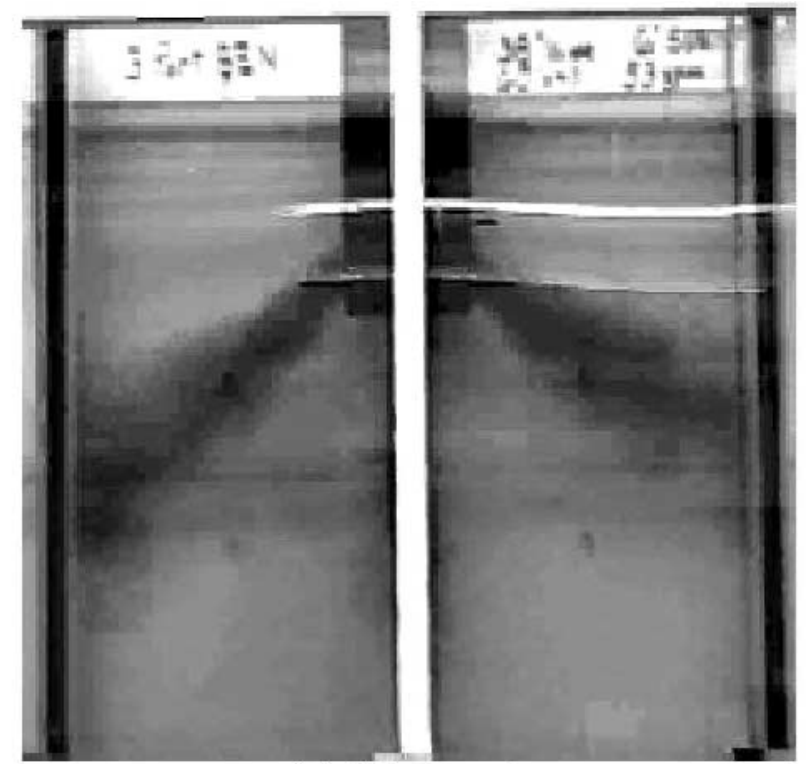

(b) 1.2 seconds

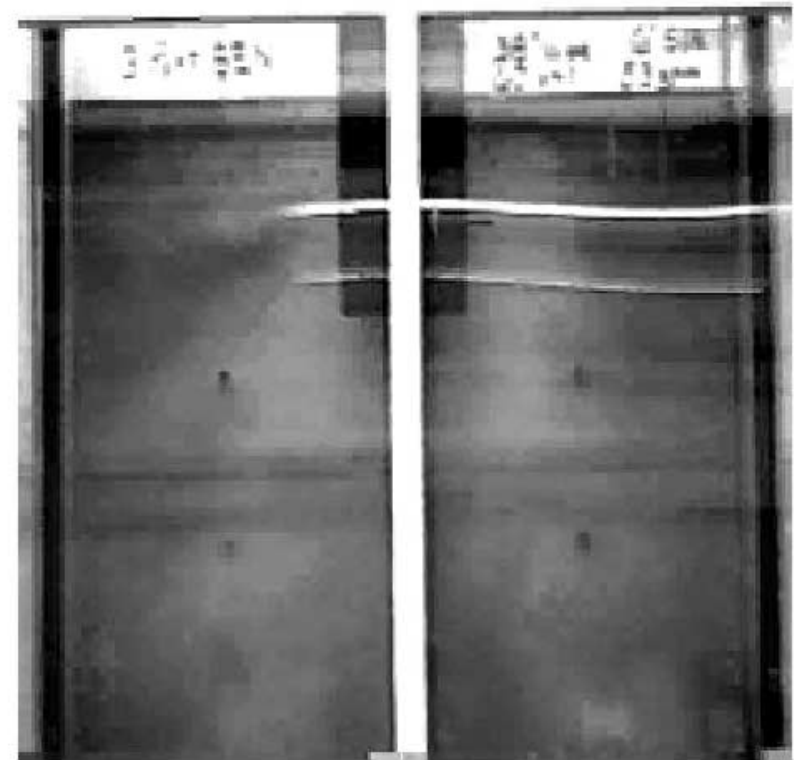

(d) 5.1 seconds

Fig. 12- (a) through $(d)$ Dye injection experiment of case 2-W at four instants.

into two parts with the flow to move into the lower and upper recirculation zones, as can be seen in the plots of Figures 12 (c) and (d). The shape of the jets and the lower and upper recirculation zones can be reconstructed from this sequence of four plots. Vortex shedding of the center jet can also be observed, although it is obscured by the external frame of the water model.

Figures 13 and 14 show a typical instantaneous velocity field and the mean field at the center plane. The mean was obtained over a time of 48.5 seconds. For clarity of presentation, the time-averaged vector plots in this work only show arrows at every second grid point in each direction. The classical double-roll flow pattern can be seen in both plots. The shape of the jets and the upper and lower recirculation zones agrees with the dye-injection observation. In contrast to the smooth time-averaged plot, the instantaneous vector plot shows local turbulent structures similar to what was seen in case 1 . The oscillation of the center jet observed in the dye injection is also seen in the simulation.

Figure 15 compares the computed time-averaged speed $\left(v_{x}^{2}+v_{z}^{2}\right)^{1 / 2}$ with the estimated value from the dye injections along the jet centerline. The solid line denotes the predicted value of the speed averaged over 48.5 seconds. The error bar shows the upper and lower bounds of the transient speed during the 48.5-second simulation, indicating a large fluctuation. The dark dots are the estimated transient flow speeds obtained by measuring the development of the dye front on the video images. The predicted values reasonably agree with the measurements.

\section{Numerical-Model Validation (Case 2-W)}

Sections $\mathrm{A}$ and $\mathrm{C}$ provide model validation with experimental measurements, comparing the predicted and measured 


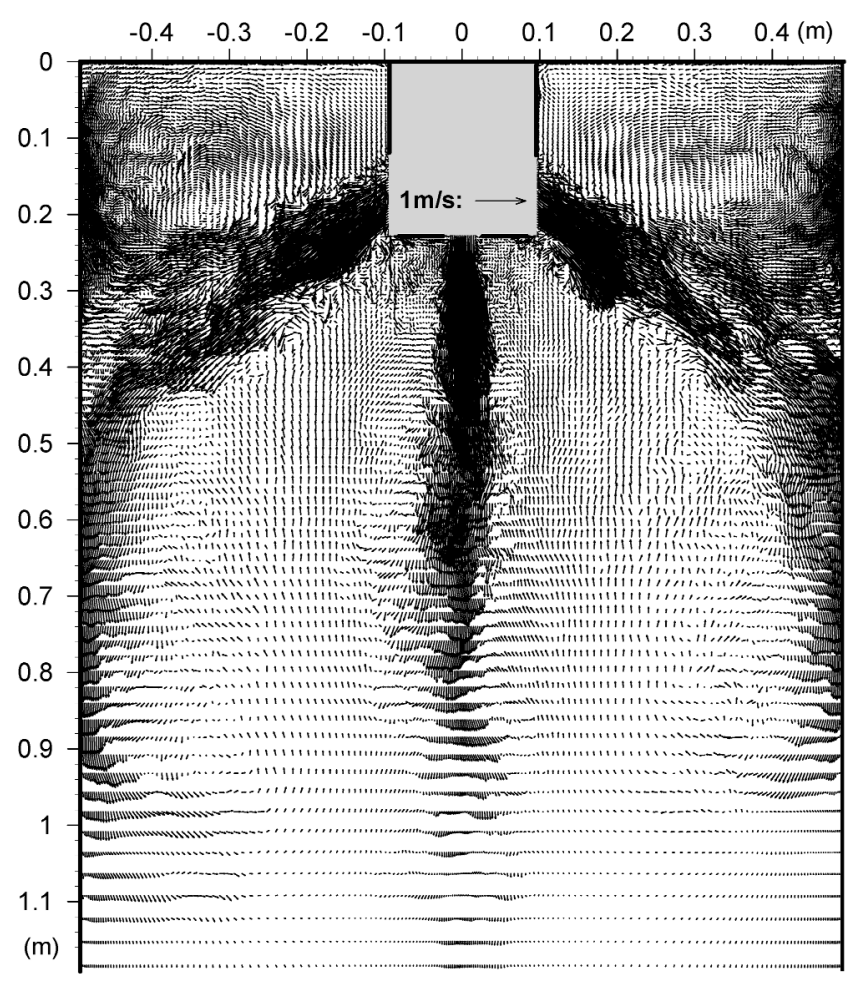

Fig. 13-Typical instantaneous velocity vector plot at the center plane between wide faces (case 2-W), obtained from simulation.

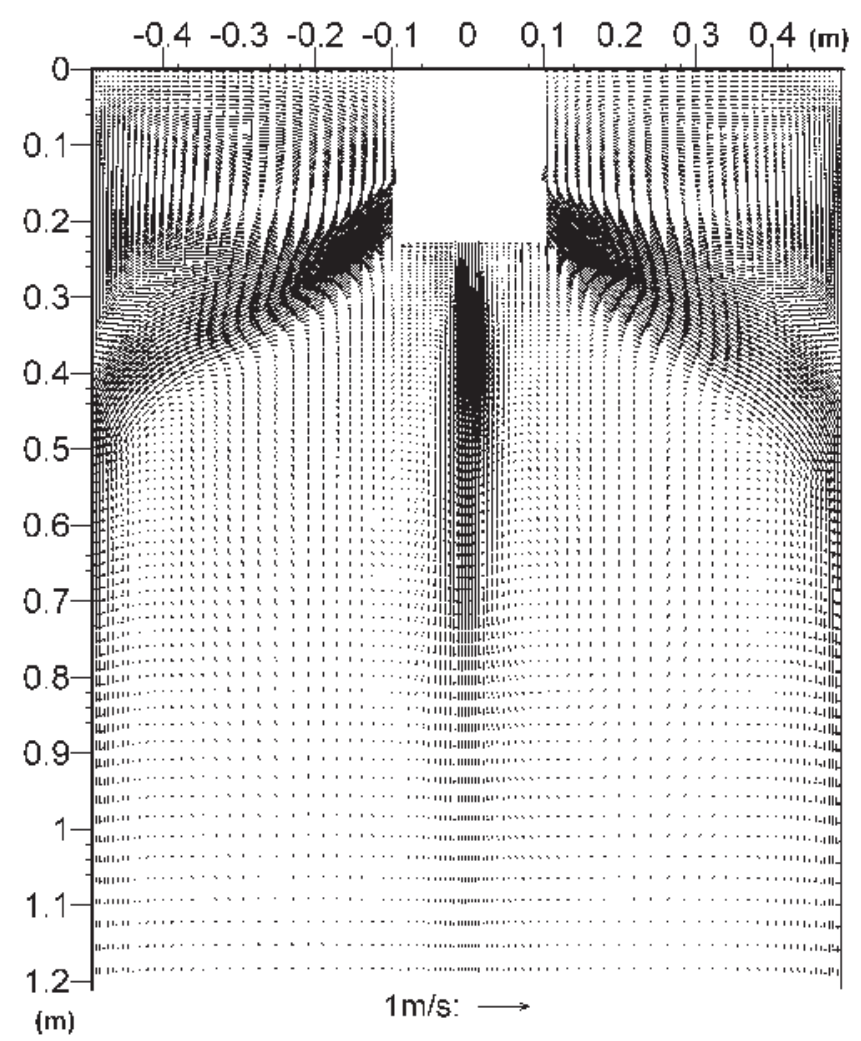

Fig. 14-Time-averaged velocity vector plot at the center plane between wide faces (case 2-W), obtained from simulation.

velocities along four vertical lines (Figure 7) and along the jet (Figure 15). Further quantitative experimental validation is provided in Sections $\mathrm{F}$ and $\mathrm{H}$ for the top-surface velocity

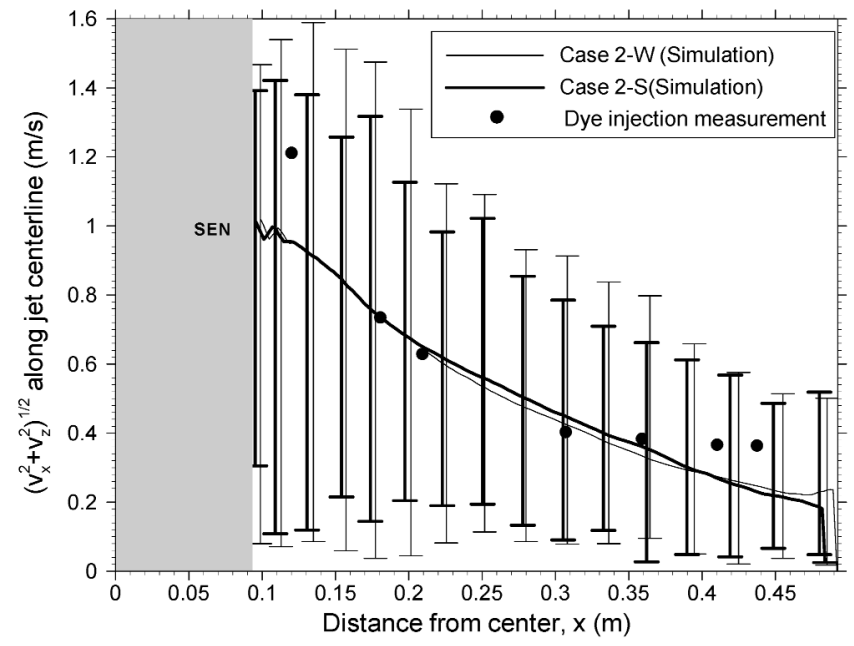

Fig. 15-Comparison of time-averaged speed $\left(v_{x}^{2}+v_{z}^{2}\right)^{1 / 2}$ along side jet centerline between computation and dye injection estimate (case $2-\mathrm{W}$ ).

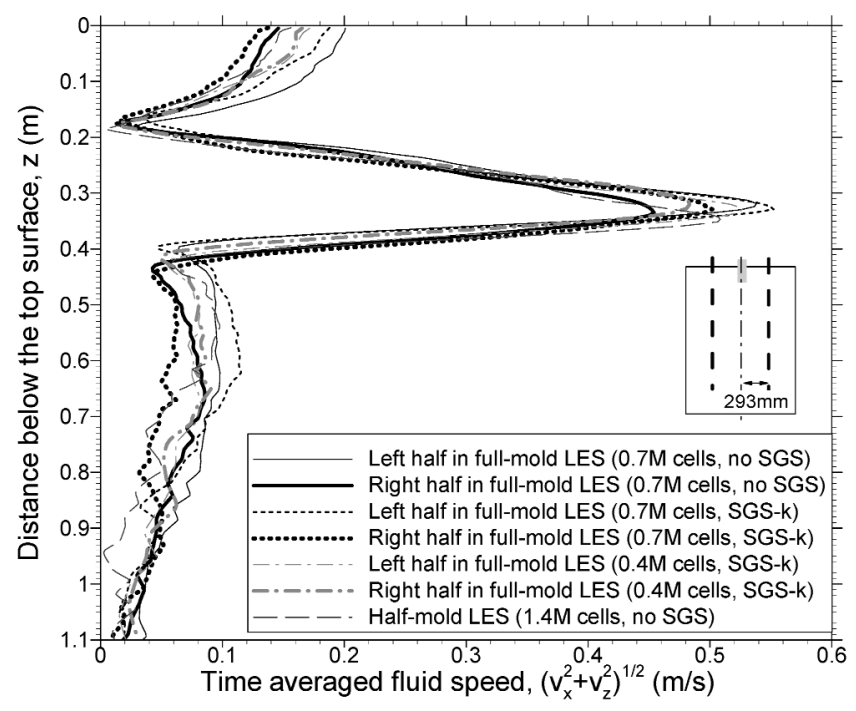

Fig. 16-Comparison of computed fluid speeds $\left(v_{x}^{2}+v_{z}^{2}\right)^{1 / 2}$ along the vertical line in the center plane, obtained from three different grid resolutions (case 2-W).

and shape, respectively. Computational models also require numerical validation to ensure that the effects of grid resolution, time-step size, turbulence model, and discretization errors associated with the order of the numerical scheme are small. Further related issues are the inlet conditions and symmetry assumption (including a half or full mold). This is a complex subject beyond the scope of this article and is discussed in detail elsewhere. ${ }^{[34,45]}$ An example is provided here in Figure 16, which compares the computed speed $\left(v_{x}^{2}+v_{z}^{2}\right)^{1 / 2}$ along a vertical line in the caster center plane, midway between the SEN and the narrow face. This figure compares results from three different computational grids: a 0.4-millionnode coarse grid, the current 0.7 -million-node grid, and a 1.4-million-node fine grid. The fine grid included only onehalf of the domain, so its node spacings are roughly 4 and 8 times finer than the other two grids, respectively. The differences between the right- and left-hand sides of the domain are more significant than the differences between grids. This indicates that the mesh resolution is adequate. This figure 


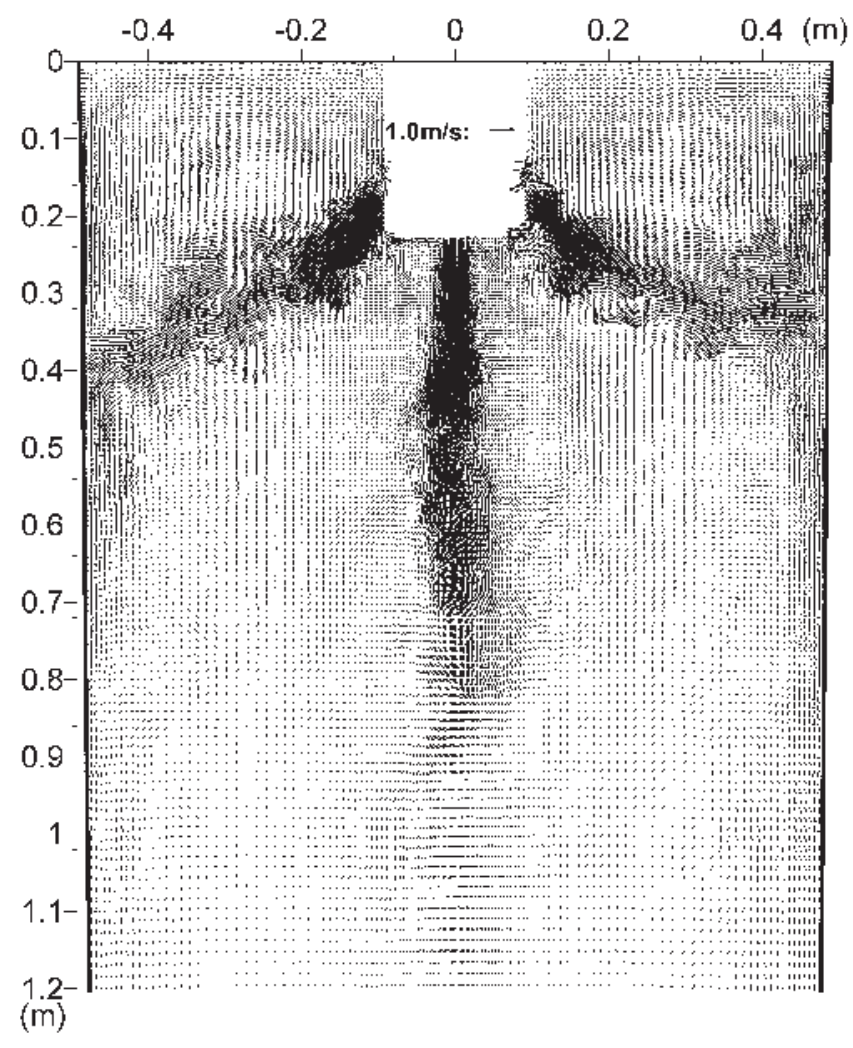

Fig. 17-Typical instantaneous velocity vector plot at the center plane between wide faces (case 2-S), obtained from simulation.

also shows that the effect of adding an SGS $k$ model $^{[46]}$ is very small. This indicates that either the unresolved small turbulent eddies are not very important, or that false diffusion from numerical discretization errors dominates over the SGS effects.

\section{E. The Thin-Slab Steel Caster (Case 2-S)}

The steel caster differs from the water model mainly in the solidifying-shell boundary and the outlet. In addition, the kinematic viscosity of the molten steel is $\sim 20$ pct smaller than that of water. These differences might lead to a different flow field in a real steel caster, even under the same operating conditions as in the water model. To investigate the flow in the real steel caster, a transient simulation of the thin-slab caster was performed using the same unsteady inlet velocities as the water model (case $2-\mathrm{W})$. The computed instantaneous and time-averaged velocity fields are presented in Figures 17 and 18 and are qualitatively similar to those of the water model. Both of the time averages of the two systems were taken over $\sim 50$ seconds. It should be noted that in both cases, the time-averaged center jet is slightly slanted to the left-hand side, indicating a long-term asymmetry. Asymmetries such as these may likely be the cause for the asymmetrical defects observed in steel products.

Figure 19 quantifies the development of the center jet. Both the time-averaged streamwise velocity $\left(v_{z}\right)$ and the rms values of all three velocity components $\left(v_{x}, v_{y}\right.$, and $\left.v_{z}\right)$ along the jet centerline are shown in the figure. The results reveal that the jet velocity decreases dramatically starting from the nozzle port. The center jet can only penetrate to around

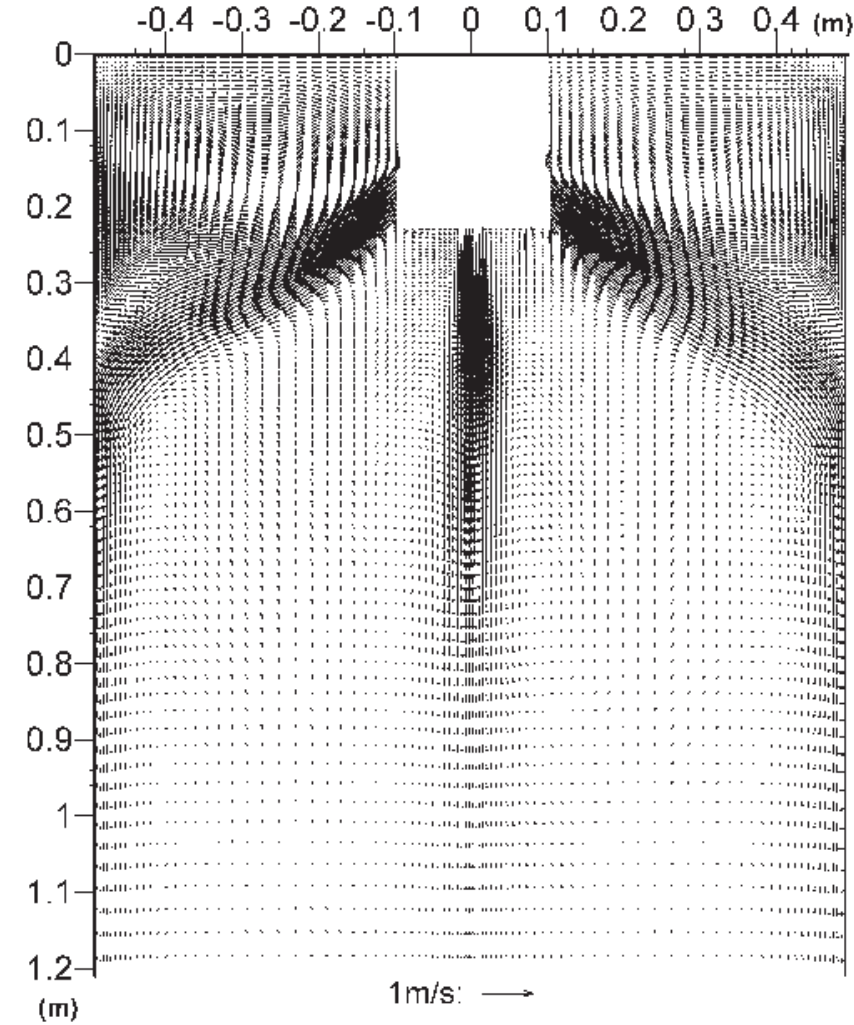

Fig. 18-Time-averaged velocity vectors at the center plane between wide faces (case 2-S), obtained from simulation.

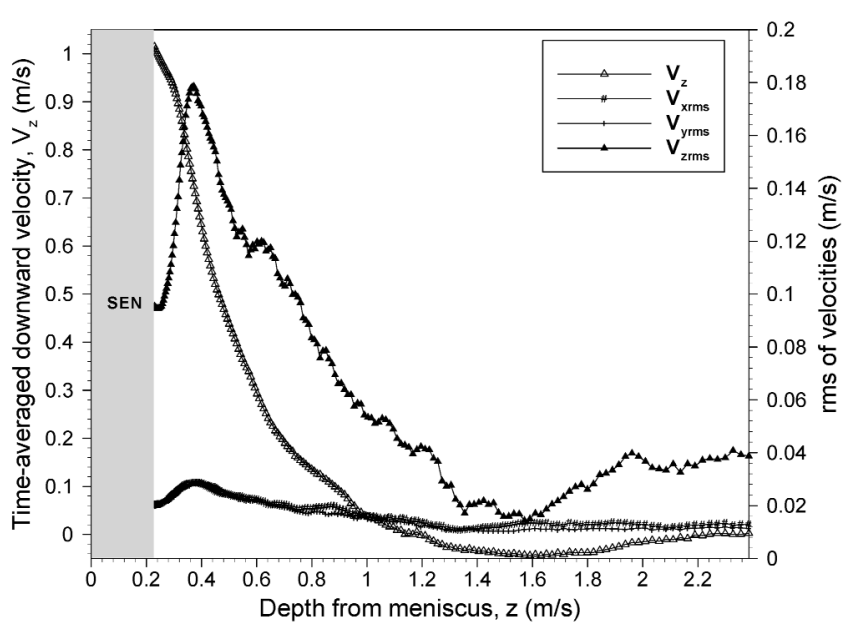

Fig. 19-Time-averaged and rms values of velocities along the center jet centerline (case 2-S).

$800 \mathrm{~mm}$ below the center nozzle port. This is important to understanding inclusion transport in the liquid pool. The results also show that the rms of the downward velocity is dominant along the center jet, suggesting a strong anisotropy of this turbulent flow.

In Figure 20, the downward velocity and rms values are presented along a line 8.5 center-port diameters below the port in the center plane $(y=0)$. The downward velocity at the jet center is seen to decrease to $\sim 45$ pct of the port outlet value. The high velocity near the narrow-face front is caused by the side jets. Because of the influence of side 


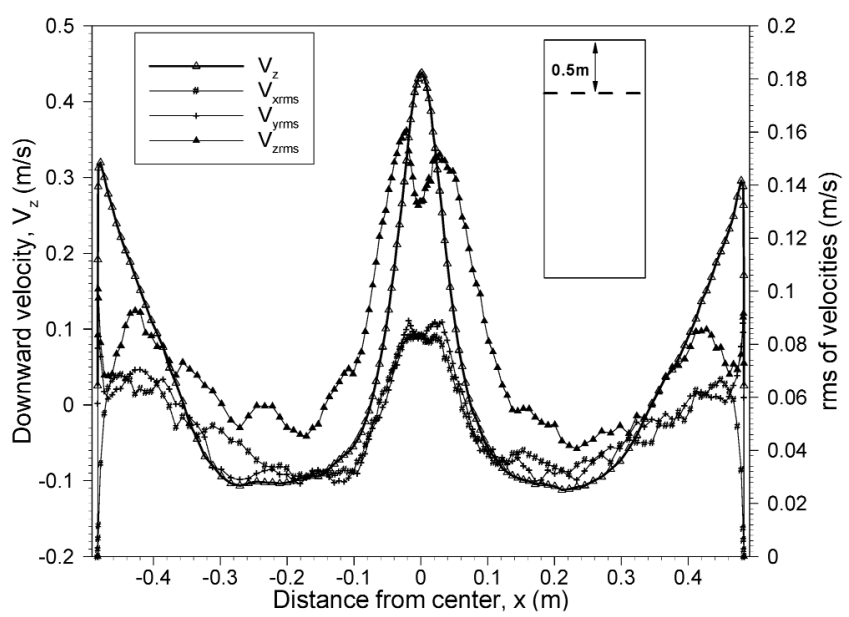

Fig. 20-Time averaged and rms values of velocities along a horizontal line $0.5 \mathrm{~m}$ below meniscus halfway between wide faces (case 2-S).

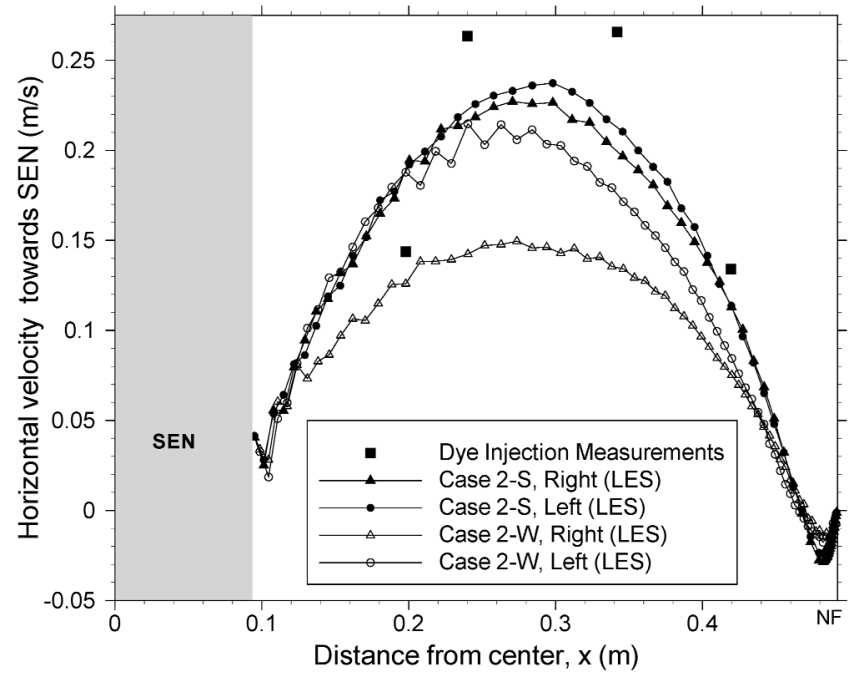

Fig. 21-Comparison of time-averaged horizontal velocity toward SEN along top surface centerline between case $2-\mathrm{W}$ and case $2-\mathrm{S}$.

jets as well as being confined by the shell, the jet width is smaller than the self-similar free jet. ${ }^{[47]}$ The rms distribution again supports the anisotropy of flow in the liquid pool.

\section{F. Comparison of the Thin-Slab Steel Caster and Its Water Model (Case 2-S vs 2-W)}

Flows in the thin-slab caster and the water model have been investigated separately. The two systems will be compared here. All the mean values presented in this section were averaged over $\sim 50$ seconds. Figure 21 presents the mean of horizontal velocity toward the SEN along the centerline on the top surface. The velocity estimated from the dye injection is also plotted as solid squares in Figure 21. All the data show a maximum velocity in the middle between the SEN and the narrow face, with a value of $\sim 0.15$ to $\sim 0.26 \mathrm{~m} / \mathrm{s}$. A significant asymmetry between the left- and right-hand sides is found in the water model (case 2-W), compared to the steel caster (case 2-S). This indicates the existence of a low-frequency (lower than $0.02 \mathrm{~Hz}$ ) oscilla-

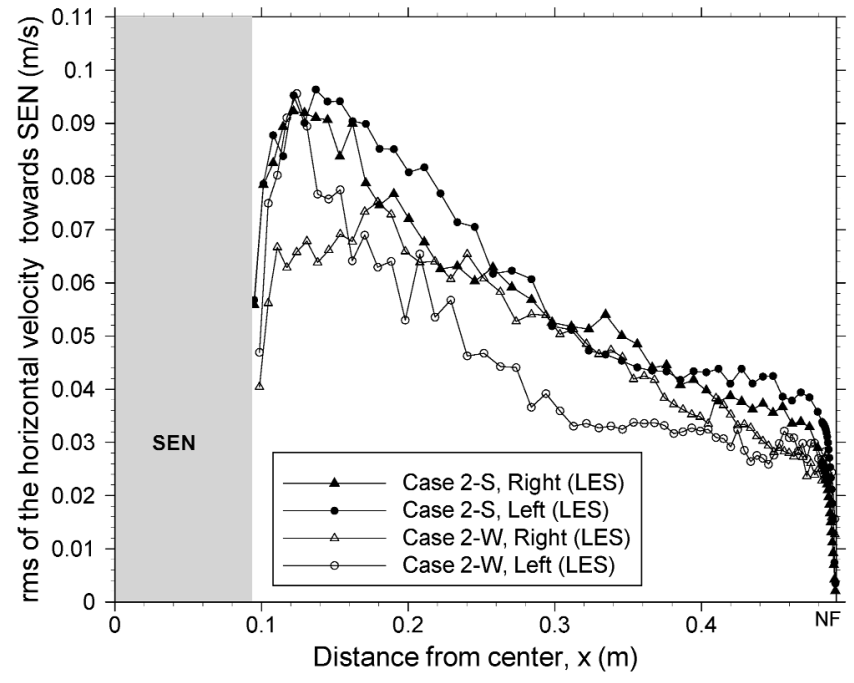

Fig. 22-Comparison of the rms values of the velocity in Fig. 21.

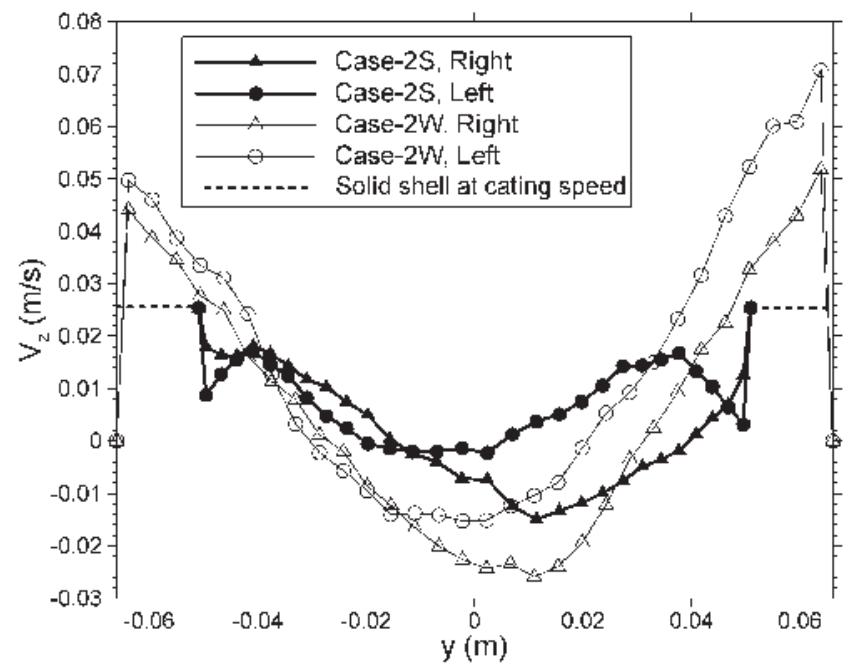

Fig. 23-Comparison of the time-averaged downward velocity between case $2-\mathrm{W}$ and case $2-\mathrm{S}$ in the lower recirculation zones.

tion between the two sides on the top surface in the water model, which is absent in the simulation of case 2-S. The downward velocity of the shell in the steel-caster simulation may have stabilized the flow so that it has less oscillation. Our previous studies of a 0.4 -scale water model ${ }^{[24,48]}$ found a similar oscillation on the top surface, with a frequency lower than $0.02 \mathrm{~Hz}$. The reason of the oscillation is still not clear. It should be also noted that the velocity on the left-hand side of the water model is very close to that of the steel caster. The rms values of the velocities in Figure 21 are presented in Figure 22. All the data suggest that the rms values reach their maximum at 15 to $30 \mathrm{~mm}$ away from the SEN and then monotonically decrease toward the narrow face. The predicted rms values are large, usually exceeding 30 pct of the local mean velocities.

Figures 23 and 24 compare the mean and rms values of the downward velocity in both systems. The data are extracted along a horizontal line $1000 \mathrm{~mm}$ below the top surface and $164 \mathrm{~mm}$ from the narrow face. Figure 23 shows a bigger spatial variation of the downward velocity for the water model. 


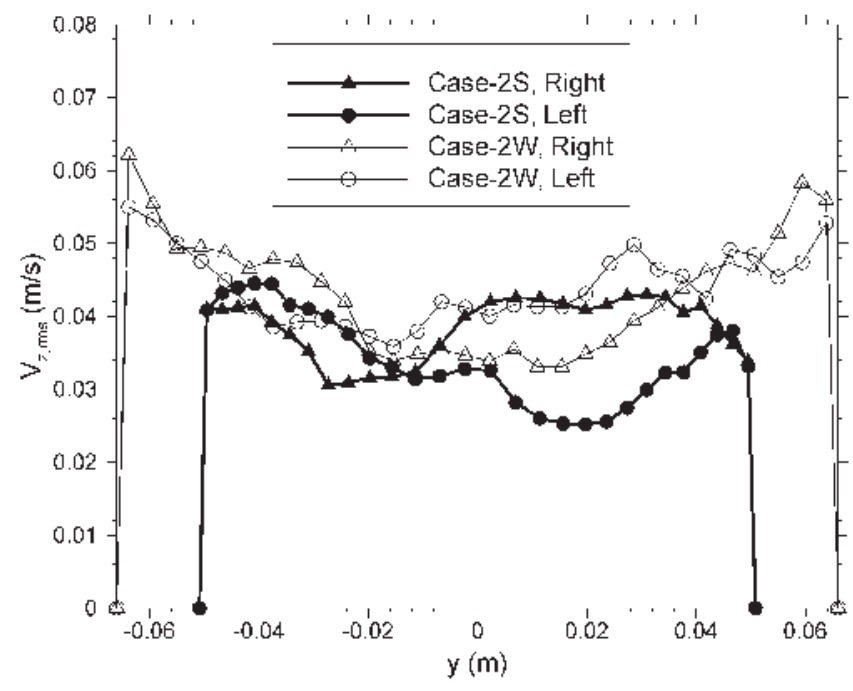

Fig. 24-Comparison of the rms values of the velocity in Fig. 23.
It shows that the steel caster has slower downward flow near the walls (where the shell is found) and less upward (or reverse) flow in the central region. This is likely due to the combined effects of tapering, which restricts the flow domain; the mass loss from solidification, which tends to even the velocity distribution; and the downward withdrawal of the shell, which pulls the flow downward at the casting speed. An asymmetry between the two sides can be seen for both the water model and the steel caster, again indicating that low-frequency oscillations exist with a period longer than 51 seconds.

\section{G. Velocity Fluctuation on Top Surface}

The top-surface velocity greatly influences the harmful entrainment of liquid slag. It fluctuates with time due to its turbulent nature. Instantaneous high values of this velocity can shear off fingers of liquid slag into the steel pool ${ }^{[49]}$ to form nonmetallic inclusions that cause serious defects. The history of surface-velocity variations is investigated in Figure 25(a), where the time signal of the computed horizontal velocity at

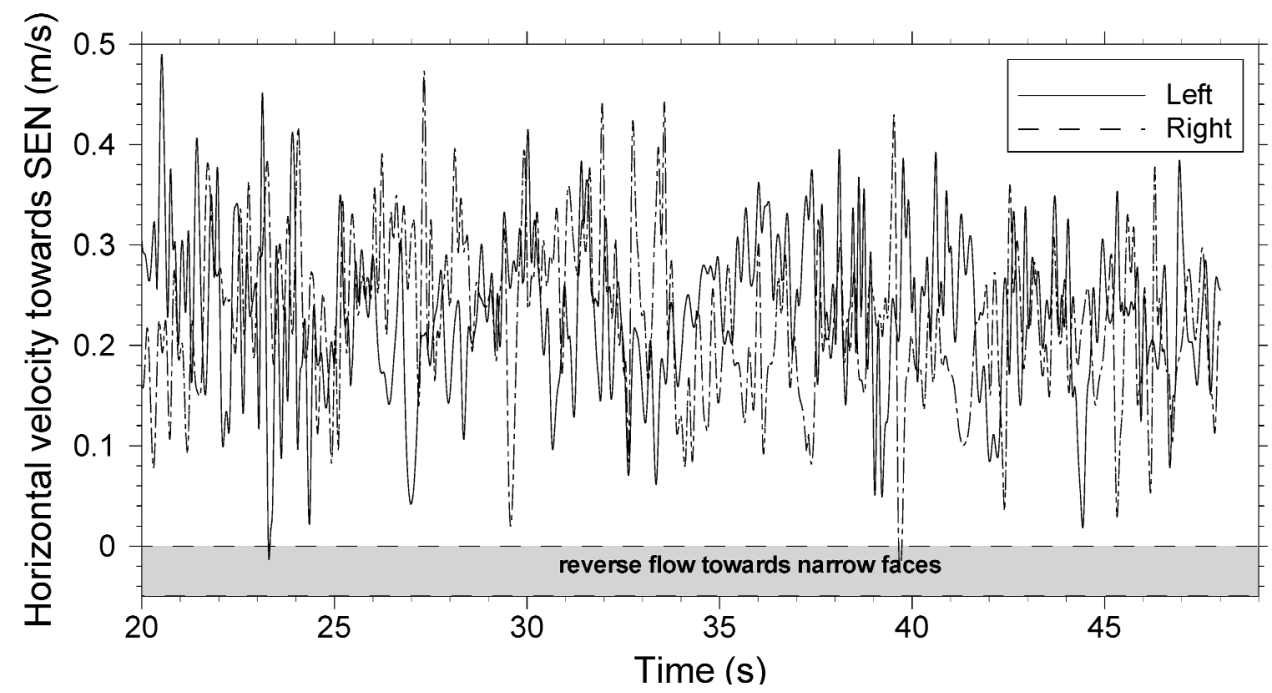

(a)

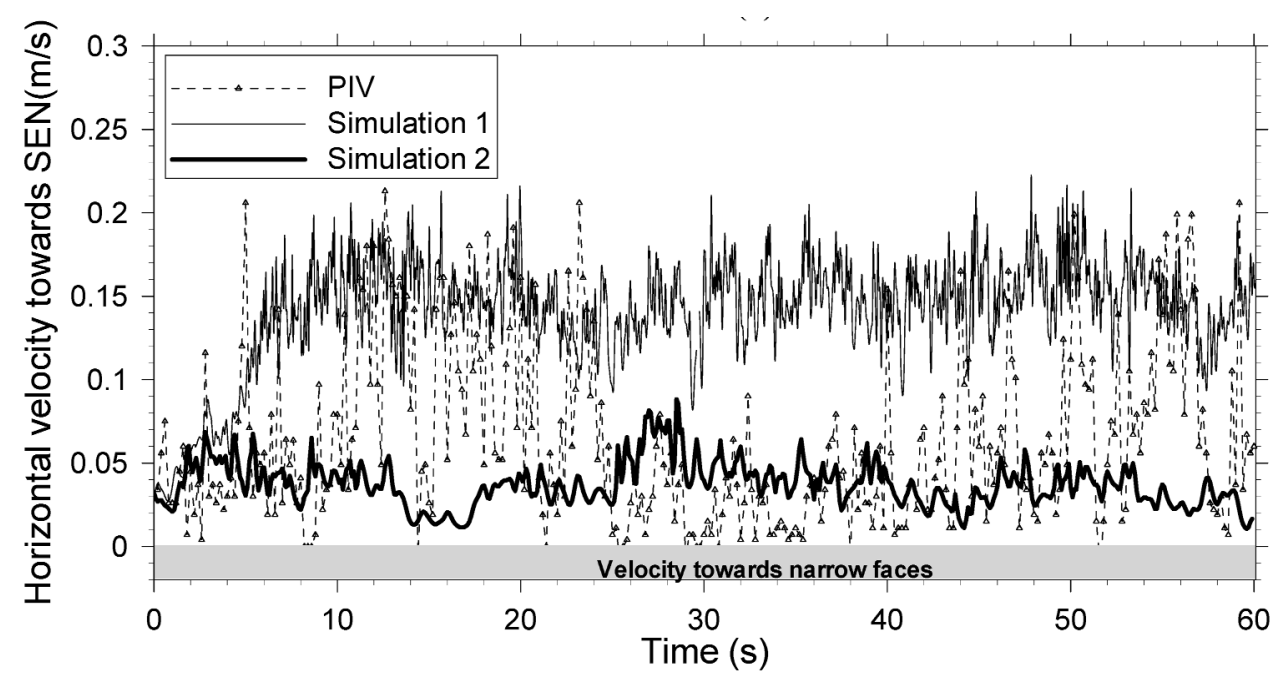

(b)

Fig. 25-Time variations of the horizontal velocity toward SEN at the center point of the top surface: $(a)$ case 2 -S and (b) a 0.4 -scale water model. ${ }^{[24]}$ 
the top-surface center point (midway between the SEN and the narrow face) for the thin-slab steel caster (case 2-S) is plotted. The velocity from the narrow face to the SEN is defined with a positive value in this plot. The figure shows that the amplitude of the fluctuation is comparable to the mean value (Figure 21). We observed that the velocity occasionally has a sudden "jump" with considerable amplitude (e.g., the flow velocity drops from $\sim 0.4 \mathrm{~m} / \mathrm{s}$ toward the SEN to the opposite direction in 0.2 seconds). Due to a lack of long-term measurements in this caster or the corresponding water model (case $2-\mathrm{W})$, this behavior is compared with our previous PIV measurements on a 0.4-scale water model shown in Figure 25(b) and published elsewhere. ${ }^{[50]}$ The figure also shows LES predictions, which were obtained from two half-pool simulations (LES1 and LES2) on the 0.4-scale water model. ${ }^{[50]}$ It is observed that the characteristic of large sudden "jumps" was also seen in the PIV measurements, but does not exist in the half-pool simulations. This suggests that transient interaction between the two halves of the caster likely causes the large sudden jumps. Half-pool simulations suppress these sudden jumps by imposing the symmetry boundary condition. The half-pool simulations may be missing other such transient phenomena, necessitating full-pool simulations.

\section{H. Liquid Level across Top Surface}

The liquid level across the top surface is important, because it affects the ability of the liquid flux to fill the interfacial gap between the mold and shell, which is important for heat transfer and, thereby, for surface quality of the final product. Figure 26 shows typical transient top-surface levels obtained from the simulation surface-pressure results for the thin-slab caster and water model. The top-surface liquid displacement $(\Delta z)$ was estimated from a simple potentialenergy balance:

$$
\Delta z(x, y)=\frac{p(x, y)-p_{\text {mean }}}{\left(\rho_{l}-\rho_{\text {top }}\right) g}
$$

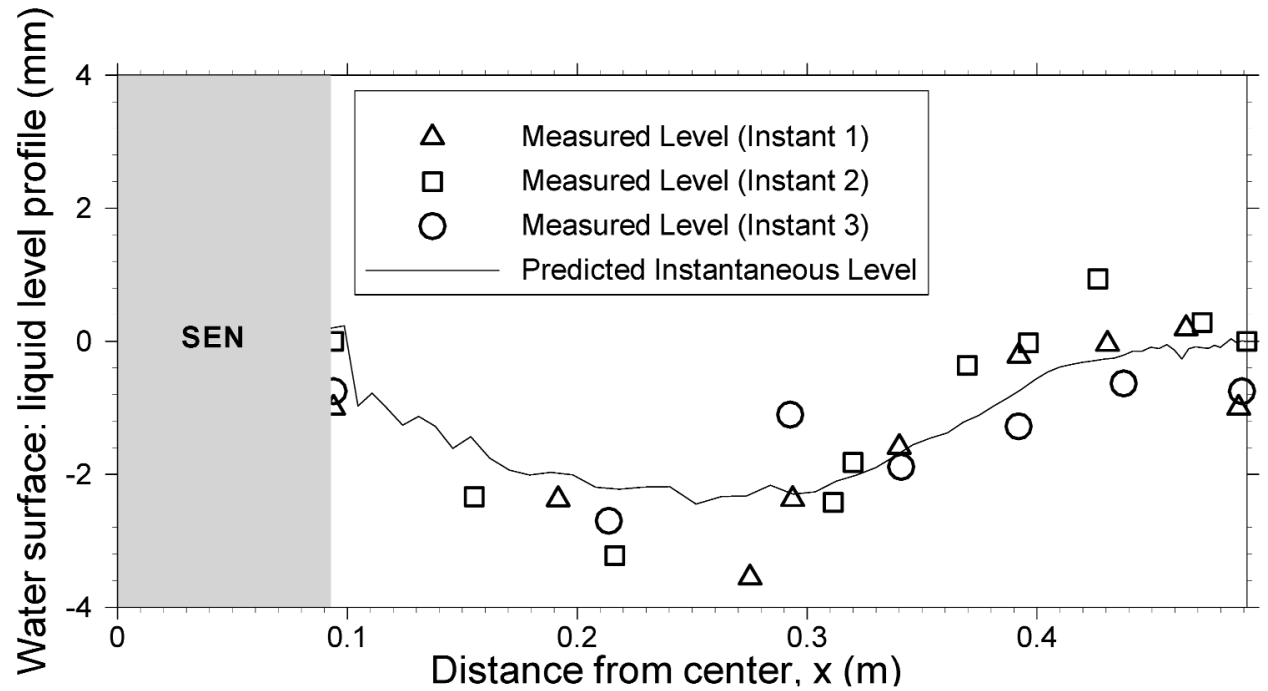

(a)

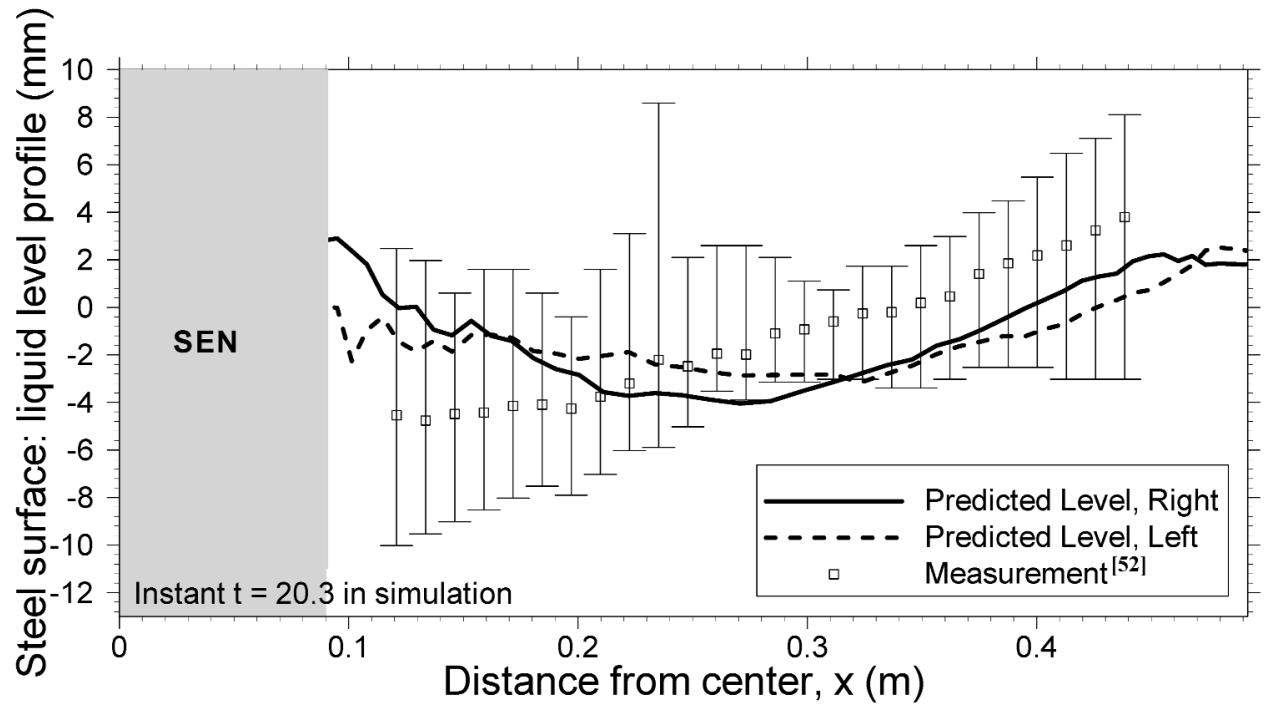

(b)

Fig. 26-Comparison of predicted and measured top surface liquid levels in (a) case 2-W and (b) Case 2-S. 
Figure 26(a) shows the water-model prediction compared with top-surface liquid profiles measured from video images at three instants. The predicted surface shape is in reasonable agreement with the measurements. It is also consistent with previous water-model results. ${ }^{[51]}$ Figure 26(b) presents the predicted molten-steel level at the top surface. The level is always higher near the narrow face, by $2 \mathrm{~mm}$ in the water model and 4 to $6 \mathrm{~mm}$ in the steel caster. This is because the upward momentum of the liquid near the narrow face lifts the liquid level there. The level change is greater in the steel system, because interface movement only requires the displacement of some molten slag. The prediction of the steel caster top-liquid profile compares reasonably with industry measurements (Figure 26(b)). ${ }^{[52]}$ Each of nine measurements was obtained by dipping a thin-steel sheet into the operating steel-caster mold and recording the slag-steel interface shape after removing it. ${ }^{[52]}$ Each point represents the mean deviation of the measurements at that location from the average surface level along the centerline. This average level was determined to be $-1.3 \mathrm{~mm}$ using Eq. [6]. The error bars indicate the range of the measurements at each location. Significant uncertainty in the measurement exists regarding possible rotation of the sheets. The slag layer needs to be thick enough to cover the steel, in order to provide a steady supply of molten flux into the interfacial gap to lubricate the steel, maintain uniform temperature profiles, and to avoid surface defects in the solid steel product. Thus, the height of this "standing wave" is important to steel quality.

\section{Asymmetries}

In most Reynolds-averaged simulations, symmetry is assumed between the flow in the two halves of the liquid pool. This assumption has been shown to be valid for longterm averages. However, transient flow in the two halves is different, for instance, on the top surface (Figures 21 and 22) and in the lower roll (Figures 23 and 24). Figure 27 further reveals the significant flow asymmetry in the lower roll. The signals present the variation of the downward velocity at two paris of monitoring points, each symmetrically located in the thin-slab steel caster. The data were sampled every 0.001 seconds from the simulation results. Shown as solid triangles, the first pair of points is located within the side jets, midway between the SEN and narrow face, $0.3 \mathrm{~m}$ below the top surface. The other pair is located at $1.2 \mathrm{~m}$ below the top surface and near ( $3.5 \mathrm{~mm}$ from) the narrow faces, to illustrate the flow in the lower recirculation zone. The plot on the top shows the velocity history at the first pair of points, which shows similar variations to those in Figure 9. No long-term asymmetries are observed between these two points in the jets. However, the plot below clearly shows that significant asymmetries can last for a relatively long time (e.g., from 37 to 40 seconds). These observations suggest that (1) low-frequency long-term asymmetries exist in the lower recirculation zone, and (2) the asymmetries are due to the turbulent nature of the flow in the liquid pool and not from asymmetries imposed by the inlet jet. This finding is important to the understanding of the behavior of inclusion particles, as particles transported to a deeper location are likely to become permanently entrapped in the steel (as discussed in detail in Part II of this article).

\section{J. Spectral Analysis}

The power spectrum ${ }^{[38]}$ of the turbulent velocity component $\left(v_{x}\right)$ was calculated at two points in the steel caster,

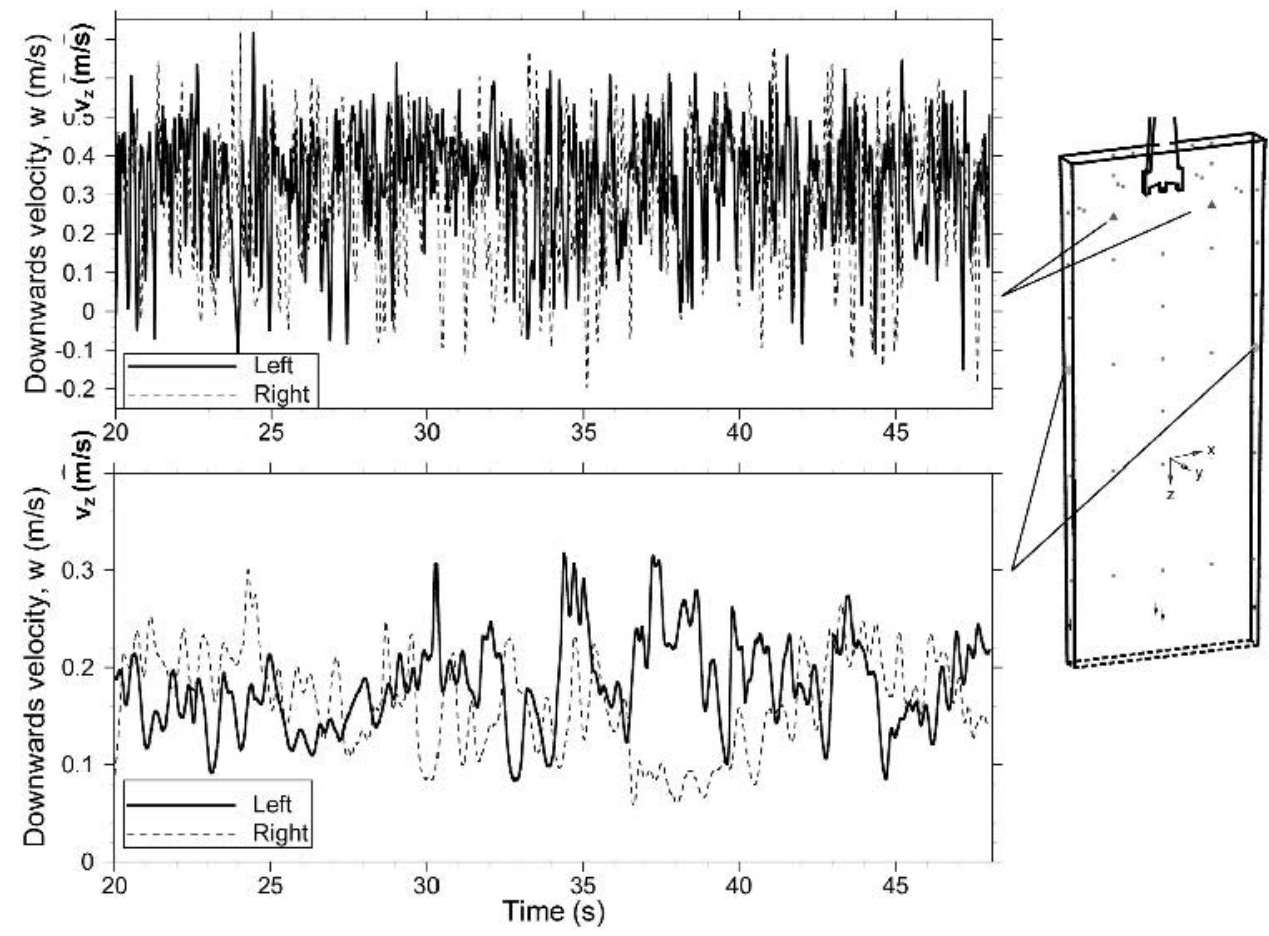

Fig. 27-Time variations of downward velocity at two pairs of symmetrical points showing low-frequency asymmetries in the lower recirculation zone (case 2-S). 


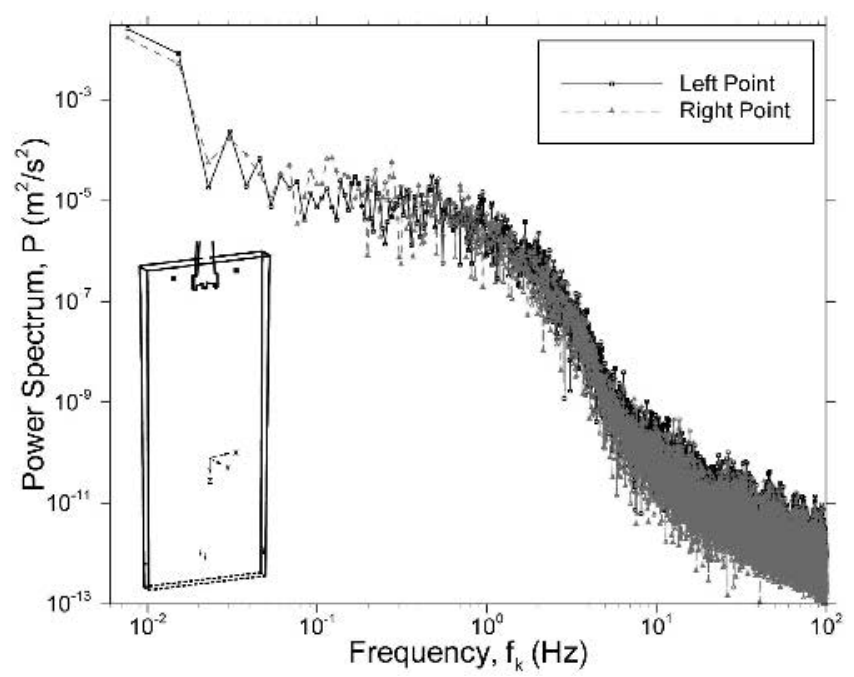

Fig. 28-Power spectrum of $v_{x}$ at two points in the upper mold, obtained from simulation data (case $2-\mathrm{S}$ ).

which are symmetrically located in the pool at a distance of $156 \mathrm{~mm}$ from the SEN outlet and at $100 \mathrm{~mm}$ below the top surface. The spectral analysis was made from $137 \mathrm{sec}-$ onds of simulation data sampled every 0.001 seconds using the following equation: ${ }^{[38]}$

$P\left(f_{k}\right)=\left\{\begin{array}{c}\frac{1}{N^{2}}\left|C_{k}\right|^{2}, \quad k=0, \frac{N}{2} \\ \frac{1}{N^{2}}\left(\left|C_{k}\right|^{2}+\left|C_{N-k}\right|^{2}\right), \quad k=1, \ldots, \frac{N}{2}-1\end{array}\right.$

where

$$
\begin{gathered}
C_{k}=\sum_{n=0}^{N-1} V_{x}\left(t_{n}\right) e^{i 2 \pi f_{k} t_{n}} \\
f_{k}=\frac{k}{t_{N-1}-t_{0}}, \quad k=-\frac{N}{2}, \ldots, \frac{N}{2}-1
\end{gathered}
$$

The result in Figure 28 shows an irregular distribution of the power spectrum, which has high maxima at low frequencies (less than $1 \mathrm{~Hz}$ ) and tends to decrease exponentially at higher frequencies, as indicated with the log-scale plot. Slight differences exist between the two points, likely due to insufficient sampling time. A similar behavior of the power spectrum was seen in measurements on a scaled water model by Lawson and Davidson. ${ }^{[53]}$

\section{CONCLUSIONS}

Three-dimensional unsteady turbulent flow in the mold region of the liquid pool of standard and thin-slab casters was computed using an in-house LES code. The computed velocity fields are compared with measurements and are seen to have reasonable agreement. The following observations are concluded from this work.

1. Complex turbulent structures are observed in the liquid pool. Two typical transient flow structures, consisting of simpler or complex multiple vortices, are found in the upper roll. The vortices break into smaller ones or emerge into bigger ones, such that the flow switches between the two patterns.

2. Flow asymmetries are found in full-pool simulations, which includes the short-term asymmetry (e.g., at the nozzle port and along the jet) and the long-term intermittent asymmetry (e.g., on the top surface and in the lower roll). The long-term asymmetry in the lower roll is due to the turbulent nature instead of asymmetries in the inflow.

3. The interaction between the two halves of the liquid pool causes important transient flow behavior (e.g., sudden jumps of top-surface velocity). Imposing an asymmetry assumption suppresses sharp sudden jumps in surface velocities and low-frequency flow transients in the lower recirculation zones.

4. Water models are generally representative of steel casters, especially in the upper region far above the watermodel outlet. However, steel casters are likely to have somewhat more evenly distributed downward flow in the lower-roll zone, where the influence of shell thickness becomes significant.

5. The top-surface level can be reasonably predicted from the top-surface pressure distribution. The top-surface level profile rises more near the narrow face in the steel caster than in the water model, which has no slag layer to displace.

6. Our analysis shows anisotropy of turbulent flow in the liquid pool. Spectral analysis suggests that most of the energy is contained in the low-frequency region (0 to $5 \mathrm{~Hz}$ ).

The flow transients and asymmetries have important effects on many other phenomena in the liquid pool that are critical to steel quality. The behavior of inclusion particles will be investigated in the second part of this article.

\section{ACKNOWLEDGMENTS}

The authors thank the National Science Foundation (Grant No. DMI-01-15486), which made this research possible. The work is also supported by the member companies of the Continuous Casting Consortium at University of Illinois at Urbana-Champaign (UIUC). Special thanks are due to Ya Meng for calculating the shell thickness, to Ron O'Malley for plant data and insights into the fluid flow, and the National Center for Supercomputing Applications (NCSA) at UIUC for computational facilities.

\section{APPENDIX}

The effect of the moving solidifying shell on the internal flow in the liquid pool can be represented using a velocity boundary condition, which is illustrated as follows. A stationary control volume in the Euler frame, shown in Figure A1, comprises a piece of solid shell. A normal velocity of the molten steel entering the control volume through the solidification front (sloped edge) can be obtained from mass conservation:

$$
\frac{d\left(\rho_{s} V\right)}{d t}=\rho_{s} A_{1} V_{\text {casting }}+\rho_{l} A_{3} v_{n}-\rho_{s} A_{2} V_{\text {casting }}
$$




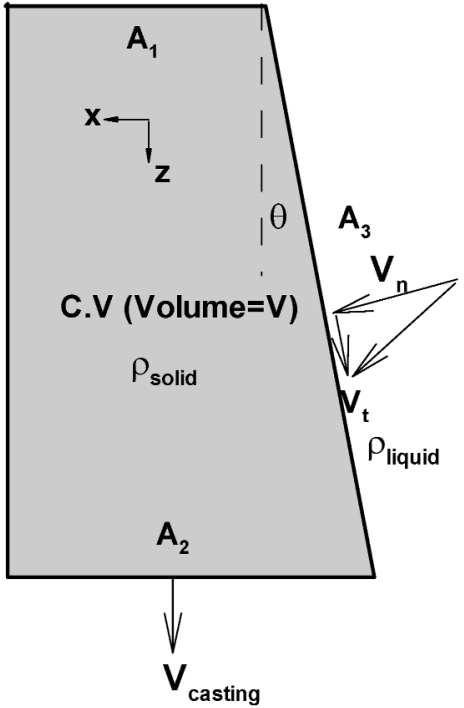

Fig. A1-The control volume for calculating boundary velocities at the shell front.

By assuming that both the shell shape and the solid density stay constant in this Eulerian frame, the normal velocity can be expressed as

$$
v_{n}=\frac{\rho_{s}\left(A_{2}-A_{1}\right)}{\rho_{l} A_{3}} V_{\text {casting }}=\left(\frac{\rho_{s}}{\rho_{l}} \sin \theta\right) V_{\text {casting }}
$$

This imposed normal velocity accounts for the mass flow caused by continuous solidification and shell withdrawal. The nonslip condition is assumed to hold tangential to the front:

$$
v_{t}=V_{\text {casting }} \cos \theta
$$

Written in terms of the $x, z$ velocity components,

$$
\begin{aligned}
& v_{x}=v_{n} \cos \theta-v_{t} \sin \theta=\left(\frac{\rho_{s}}{\rho_{l}}-1\right) \sin \theta \cos \theta V_{\text {casting }} \\
& v_{z}=v_{n} \sin \theta+v_{t} \cos \theta=\left(\frac{\rho_{s}}{\rho_{l}} \sin ^{2} \theta+\cos ^{2} \theta\right) V_{\text {casting }}
\end{aligned}
$$

Eq. [A4] gives the velocity boundary condition at the shell front position. The value of $\theta$ is evaluated at each distance, $z$, from the slope of the shell thickness profile, given by CON1D in Figure 3. No adjustment is needed for inside and outside radii because the top $3 \mathrm{~m}$ of the caster is straight.

\section{NOMENCLATURE}

$\frac{D}{D t} \quad$ total derivative $\left(=\frac{\partial}{\partial t}+v_{j} \frac{\partial}{\partial x_{j}}\right)$

$x_{i} \quad$ coordinate direction $(x, y$, or $z)$

$v_{i} \quad$ velocity component

$\nu_{0} \quad$ kinematic viscosity of fluid

$\nu_{\text {eff }} \quad$ effective viscosity of turbulent fluid $\rho$ density

$p \quad$ static pressure

$p_{\text {mean }}$ average pressure over top surface

$t \quad$ time

$g \quad$ gravity acceleration $\left(9.81 \mathrm{~m}^{2} / \mathrm{s}\right)$

$P \quad$ power spectrum defined in Eq. [7a]

$\left|C_{k}\right|$ modulus of $C_{k}$ in Eq. [7b]

$f_{k} \quad$ frequency defined in Eq. [7c]

$i \quad \sqrt{-1}$

A area

$V_{\text {casting }}$ casting speed

$N \quad$ total sampling time steps in Eq. [7]

$\underline{\text { Subscripts }}$

$l \quad$ fluid (liquid steel or water)

$s \quad$ solid

top top surface material (air or slag)

$n, t$ normal, tangential

$i, j \quad$ direction $(x, y$, or $z)$ repeated indices imply summation

\section{REFERENCES}

1. R.C. Sussman, M. Burns, X. Huang, and B.G. Thomas: 10th Process Technol. Conf. Proc., ISS, Warrendale, PA, 1992, vol. 10, pp. 291-304.

2. Y. Ho, C. Chen, and W. Hwang: Iron Steel Inst. Jpn. Int., 1994, vol. 34 (3), pp. 255-64.

3. B. Grimm, P. Andrzejewski, K. Muller, and K.-H. Tacke: Steel Res., 1999, vol. 70 (10).

4. X. Huang, B.G. Thomas, and F.M. Najjar: Metall. Trans. B, 1992, vol. 23B, pp. 339-56.

5. D. Gupta and A.K. Lahiri: Metall. Mater. Trans. B, 1994, vol. 25B, pp. 227-33.

6. A. Theodorakakos and G. Bergeles: Metall. Mater. Trans. B, 1998, vol. 29B, pp. 1321-27.

7. J. Herbertson, Q.L. He, P.J. Flint, and R.B. Mahapatra: Steelmaking Conf. Proc., ISS, Warrendale, PA, 1991, vol. 74, pp. 171-85.

8. G.D. Lawson, S.C. Sander, W.H. Emling, A. Moitra, and B.G. Thomas: Steelmaking Conf. Proc., ISS, Warrendale, PA, 1994, vol. 77, pp. 329-36.

9. R. Bommaraju, R. Glennon, and M. Frazee: in Continuous Casting, M. Wolf, ed., ISS, Warrendale, PA, 1997, vol. 9, pp. 307-18.

10. B.G. Thomas, D. Lui, and B. Ho: in Applications of Sensors in Materials Processing, V. Viswanathan, ed., TMS, Warrendale, PA, 1997, pp. $117-42$.

11. T.J.H. Billany, A.S. Normanton, K.C. Mills, and P. Grieveson: Ironmaking and Steelmaking, 1991, vol. 18, pp. 403-10.

12. W.H. Emling, T.A. Waugaman, S.L. Feldbauer, and A.W. Cramb: Steelmaking Conf. Proc., Chicago, IL, Apr. 13-16, 1997, ISS, Warrendale, PA, 1994, vol. 77, pp. 371-79.

13. J. Knoepke, M. Hubbard, J. Kelly, R. Kittridge, and J. Lucas: Steelmaking Conf. Proc., Chicago, IL, Mar. 20-23, 1994, ISS, Warrendale, PA, 1994, vol. 77 , pp. $381-88$.

14. J. Szekely and R.T. Yadoya: Metall. Mater. Trans., 1973, vol. 4, pp. $1379-88$.

15. S.K. Choudhary and D. Mazumdar: Iron Steel Inst. Jpn. Int.. 1994. vol. 34 (7). pp. 584-92.

16. S.K. Choudhary and D. Mazumdar: Steel Res.. 1995, vol. 66 (5), pp. $199-205$

17. B.G. Thomas and L.M. Mika: 2nd FIDAP Users Conf., Evanstan, IL, 1988, M. Engelman, ed., Fluid Dynamics International Inc., Evanston, IL, 1988, pp. 1-29.

18. B.G. Thomas, F.M. Najjar, and L.J. Mika: Proc. F. Weinberg Int. Symp. on Solidification Processing, 29th Canadian Institute of Mining and Metallurgy Conf., Hamilton, ON, 1990, J.E. Lait and I. V. Samarasekera, eds., Pergamon Press, Inc., Toronto, 1990, pp. 131-45.

19. B.G. Thomas, L.M. Mika, and F.M. Najjar: Metall. Trans. B, 1990, vol. $21 \mathrm{~B}$, pp. $387-400$.

20. B.G. Thomas and F.M. Najjar: Appl. Mathematical Modeling, 1991, vol. 15 , pp. 226-43.

21. B.G. Thomas, Q. Yuan, S. Sivaramakrishnan, T. Shi, S.P. Vanka, and M.B. Assar: Iron Steel Inst. Jpn. Int., 2001, vol. 41 (10), pp. 1262-71. 
22. B.G. Thomas and L. Zhang: Iron Steel Inst. Jpn. Int., 2001, vol. 41 (10), pp. 1181-93.

23. X. Huang and B.G. Thomas: 35th Conf. Metallurgists, C. Twigge-Molecey, ed., CIM, 1996, vol. 23B, pp. 339-56.

24. S. Sivaramakrishnan, H. Bai, B.G. Thomas, P. Vanka, P. Dauby, and M. Assar: Ironmaking Conf. Proc., ISS, Warrendale, PA, 2000, vol. 59, pp. 541-57.

25. Q. Yuan, S.P. Vanka, and B.G. Thomas: 2nd Int. Symp. on Turbulent and Shear Flow Phenomena, Stockholm, 2001, Royal Insitute of Technology (KTH), Stockholm, 2001, p. 6.

26. K. Takatani, Y. Tanizawa, H. Mizukami, and K. Nishimura: Iron Steel Inst. Jpn. Int., 2001, vol. 41 (10), pp. 1252-61.

27. R. Sobolewski and D.J. Hurtuk: 2nd Process Technology Conf. Proc., ISS, Warrendale, PA, 1982, vol. 2, pp. 160-65.

28. B.G. Thomas, X. Huang, and R.C. Sussman: Metall. Trans. B, 1994, vol. 25B, pp. 527-47.

29. D. Gupta and A.K. Lahiri: Metall. Mater. Trans. B, 1996, vol. 27B, pp. 757-64.

30. D. Gupta, S. Chakraborty, and A.K. Lahiri: Iron Steel Inst. Jpn. Int., 1997, vol. 37 (7), pp. 654-58.

31. S. Sivaramakrishnan, B.G. Thomas, and S.P. Vanka: in Materials Processing in the Computer Age, V. Voller and H. Henein, eds., TMS, Warrendale, PA, 2000, vol. 3, pp. 189-98.

32. M.B. Assar, P.H. Dauby, and G.D. Lawson: Steelmaking Conf. Proc., ISS, Warrendale, PA, 2000, vol. 83, pp. 397-411.

33. J. Smagorinsky: Monthly Weather Rev., 1963, vol. 91, pp. 99-164.

34. Q. Yuan, B. Zhao, S.P. Vanka, and B.G. Thomas: University of Illinois at Urbana-Champaign, Urbana, IL, unpublished research, 2004.

35. F.H. Harlow and J.E. Welch: Phys. Fluids, 1965, vol. 8 (112), pp. 2182-89.

36. J. Crank and P. Nicolson: Proc. Cambridge Phil. Soc., 1947, vol. 43, pp. 50-67.

37. L.F. Sampine and M.K. Gordon: Computer Solution of Ordinary Differential Equations: the Initial Value Problem, W.H. Freeman \& Co., San Francisco, CA, 1975.
38. W.H. Press, S.A. Teukolsky, W.T. Vetterling, and B.P. Flannery: Numerical Recipes: The Art of Scientific Computing, Cambridge University Press, Cambridge, United Kingdom, 1992, pp. 490-600.

39. User's Manual: Hypre-High Performance Preconditioners, Report No. UCRL-MA-137155 DR, Center for Applied Scientific Computing, Lawrence Livermore National Laboratory, Livermore, CA, 2001.

40. B.G. Thomas, R. O'Malley, T. Shi, Y. Meng, D. Creech, and D. Stone: in Modeling of Casting, Welding, and Advanced Solidification Processes, Shaker Verlag GmbH, Aachen, Germany, 2000, vol. IX, 2000, pp. 769-76.

41. Y. Meng and B.G. Thomas: Metall. Mater. Trans. B, 2003, vol. 34B. pp. $685-705$.

42. B.G. Thomas, R.J. O'Malley, and D.T. Stone: in Modeling of Casting, Welding, and Advanced Solidification Processes, San Diego, CA, 1998, B.G. Thomas and C. Beckermann, eds., TMS, Warrendale, PA, 1998, vol. VIII, pp. 1185-99.

43. F.M. Najjar, B.G. Thomas, and D.E. Hershey: Metall. Trans. B, 1995, vol. 26B, pp. 749-65.

44. H. Bai and B.G. Thomas: Metall. Mater. Trans. B, 2001, pp. 269-84.

45. B. Zhao, B.G. Thomas, S.P. Vanka, and R.J. O'Malley: University of Illinois at Urbana-Champaign, Urbana, unpublished research, 2003.

46. K. Horiuti: J. Phys. Soc. Jpn., 1985, vol. 54 (8), pp. 2855-65.

47. I. Wygnanski and H. Fiedler: J. Fluid Mech., 1969, vol. 38, pp. 577-612.

48. S. Sivaramakrishnan: Master's Thesis, University of Illinois, Urband, IL, 2000.

49. A. Cramb, Y. Chung, J. Harman, A. Sharan, and I. Jimbo: Iron Steelmaker. 1997, vol. 24 (3), pp. 77-83.

50. Q. Yuan, T. Shi, B.G. Thomas, and S.P. Vanka: Proc.: Computational Modeling of Materials, Minerals and Metals Processing, Seattle, WA, 2001, TMS, Warrendale, PA, 2001, pp. 491-500.

51. J. Anagnostopoulos and G. Bergeles: Metall. Mater. Trans. B, 1999. vol. 30B, pp. 1095-1105.

52. R.J. O'Malley: AK Steel, Middltown, OH, private communication, 2002.

53. N.J. Lawson and M.R. Davidson: J. Fluids Eng., 2002, vol. 124 (6), pp. 535-43. 